\title{
DIAGNOSIS AND TREATMENT OF TRICUSPID STENOSIS
}

\author{
BY \\ ARTHUR KITCHIN AND RICHARD TURNER \\ From The Cardiac Department, Western General Hospital, and The Department of Medicine, \\ University of Edinburgh \\ Received August 1, 1963
}

It has often been pointed out that tricuspid stenosis occurs much more frequently than it is diagnosed. This may be because it so rarely occurs as a single valvular defect (although such cases have been described), because there are no characteristic symptoms, and because clinical signs are often inconspicuous. In the past, it has not been considered of much practical importance to make the diagnosis but this is no longer the case owing to the availability of surgical treatment. Tricuspid stenosis is usually of rheumatic origin, but the condition may be congenital (Paul and Lev, 1960) and has been reported in carcinoid (Millman, 1943), fibro-elastosis (Dennis, Hansen, and Corpening, 1953), endomyocardial fibrosis (Davies and Ball, 1955), and lupus erythematosus (Gibson and Wood, 1955). The condition has been simulated by a right atrial myxoma (Lyons et al., 1958).

This paper is concerned with the diagnosis, circulatory effects, and surgical treatment of rheumatic tricuspid stenosis associated with severe mitral stenosis, with particular reference to 17 patients who were studied in detail and then treated by combined valvotomy. It is noteworthy that we have not seen or at least not recognized severe tricuspid stenosis in association with isolated mitral incompetence or isolated aortic valvular disease.

\section{INCIDENCE}

In autopsy studies of rheumatic heart disease the published incidence of tricuspid stenosis has been high, varying between 22 and 44 per cent. In seven combined series, 240 out of a total of 806 cases of rheumatic heart disease were found to have tricuspid stenosis, an incidence of 30 per cent (Coombs, 1924; Cabot, 1926; Von Glahn, 1927; Thayer, 1925; Cooke and White, 1941; Aceves and Carral, 1947). In a clinical series Coombs (1924) estimated the incidence at 14 per cent. Bailey and Bolton (1956) explored the tricuspid valve in 98 patients undergoing mitral valvotomy for mitral stenosis, and found significant tricuspid stenosis in 15, in only 3 of whom the diagnosis had been made before operation. In our hospital, in a consecutive series of 100 autopsies carried out on cases of rheumatic heart disease during the time of the present clinical study, the incidence of tricuspid narrowing to admit three fingers or less $(10 \mathrm{~cm}$. circumference) was 14 per cent, and out of 550 consecutive patients subjected to mitral valvotomy the diagnosis of severe tricuspid stenosis (valve area $=$ $1.5 \mathrm{~cm} .{ }^{2}$ or less) was made and confirmed in 17 cases at operation, an incidence of 3.1 per cent.

It is evident that the apparent incidence of tricuspid stenosis depends on the criteria used for diagnosis. Cabot (1926) gives the circumference of the normal tricuspid valve as $12-14 \mathrm{~cm}$., and most pathologists seem to have taken a circumference of less than 10-11 cm. (i.e. diameter less than $2 \mathrm{~cm}$. or a valve area of $7 \mathrm{~cm}^{2}$ ) to indicate stenosis. White (1944) expresses the view that the disease cannot be recognized clinically unless the valve circumference is less than $8 \mathrm{~cm}$. (diameter $2.5 \mathrm{~cm}$., valve area $4.9 \mathrm{~cm}^{2}$ ), and we are in agreement with this. Ferrer et al. (1953) consider that recognition 
of tricuspid stenosis is only feasible in advanced cases. The critical size of orifice at which obstruction seriously impairs the circulation and requires surgical relief has not been established. In the case of the mitral valve it is generally taken to be $1.5 \mathrm{~cm} .^{2}$ and, as will be discussed in this paper, there is reason to believe that it may be somewhat greater for the tricuspid valve. It is clear, however, that the pathological criteria that have been used include many cases of mild narrowing which would not be expected to give rise to significant symptoms, signs, or hæmodynamic effects, and this explains the greater incidence at necropsy than in clinical series.

The objects of the present study are threefold; first, to investigate the diagnostic criteria for tricuspid stenosis; secondly, to assess the effects on the circulation; and, thirdly, to consider the indications for and results of surgical treatment in the light of our clinical experience.

\section{Diagnostic CRITERIA}

The first purpose of this study is the correlation of physical signs, radiographic and electrocardiographic findings, and hæmodynamic data with the size of the valve orifice found at operation, in order to establish criteria for the diagnosis of significant stenosis, that is to say a valve of $1.5 \mathrm{~cm} .^{2}$ or less in area.

Many points in published work require clarification. In the last edition of the New York Heart Association handbook on criteria (1953) the classical picture of a patient with tricuspid stenosis is said to include cyanosis, jaundice, distended, pulsating neck veins, enlarged pulsating liver, and ascites. In the past 15 years we have not encountered such a picture from tricuspid stenosis and believe, on the contrary, that this is the picture of advanced tricuspid incompetence.

Answers are needed to the following questions: (1) Is the jugular venous pulse a reliable guide to tricuspid stenosis, and in this condition how is it modified by atrial fibrillation and by tricuspid incompetence?

(2) Are tricuspid murmurs any guide to the degree of stenosis, and what is the significance of respiratory variations in the murmurs? Can a tricuspid diastolic murmur be solely derived from incompetence as has been claimed for organic mitral incompetence? Is an organically stenosed tricuspid valve always also incompetent?

(3) How characteristic are the radiological signs of a dilated right atrium, clear lung fields, or absence of enlargement of the pulmonary artery?

(4) How diagnostic of tricuspid stenosis are tall peaked $\mathrm{P}$ waves in the electrocardiogram, and in patients with rheumatic heart disease can similar P waves occur from tricuspid incompetence or from pulmonary hypertension without tricuspid disease? Is a pattern of right ventricular hypertrophy compatible with severe tricuspid stenosis?

(5) At what time in diastole is a pressure gradient across the tricuspid valve most significant? What pressure gradient suggests severe stenosis, and what is the effect on the gradient of tricuspid incompetence and of atrial fibrillation?

\section{HÆMODYNAMIC EFFECTS}

The second object of this paper is to study the circulatory effects of tricuspid valve obstruction. Tricuspid stenosis will affect cardiac output and systemic venous pressure and may also be expected to modify the pulmonary arterial and venous hypertension due to associated mitral valve obstruction. We have studied the changes in these four variables at rest and on exercise and compared the results with cases of isolated mitral stenosis.

\section{SURGICAL TREATMENT}

Lastly, and combining the diagnostic and hæmodynamic parts of the study, there is the question of indications for surgical treatment. This depends on determining a critical size for the valve below which serious hæmodynamic effects are produced. Ordinarily the assessment of results 
would be made on the basis of symptoms and signs, radiography and electrocardiography, but this is inconclusive if mitral valvotomy is carried out at the same time. It is necessary to accept the degree of symptomatic improvement, the observations of the surgeon as to the degree of valvular stenosis or incompetence found and what was achieved by valvotomy, regression of manifestations attributable to tricuspid disease, and the results of recatheterization studies. Some have questioned the need for tricuspid valvotomy (R. C. Brock, 1953, quoted by Chesterman and Whitaker, 1954) on the grounds that mitral valvotomy is always sufficient to relieve symptoms. The danger of producing traumatic tricuspid incompetence has been stressed on anatomical grounds by Hollman (1956), and partial commissurotomy only has been recommended (Bailey, 1955; Pantridge and Marshall, 1957).

The indications for operation and the results of surgery are discussed on the basis of the 17 cases treated.

\section{The Present Series}

In a consecutive series of 550 patients subjected to mitral valvotomy from our unit a clinical diagnosis of severe associated tricuspid stenosis was supported by the findings at cardiac catheterization in 19 cases: in 2 the diagnosis was confirmed at autopsy; in 17 tricuspid valvotomy was performed immediately after relief of the mitral stenosis. In 5 other patients, although severe tricuspid stenosis was considered unlikely, it was thought justifiable to explore the right atrium in view of the presence of a pressure gradient in diastole across the tricuspid valve in order to ascertain the size of the valve and thus assist in the establishment of diagnostic criteria. In fact in this group the gradient was found to result from dominant tricuspid incompetence.

Clinical Assessment. All patients were assessed in hospital. In view of the frequency with which tricuspid valvular disease is overlooked particular care was taken to detect this condition in each case by noting any discrepancy between severity of symptoms and physical signs, by careful attention to the jugular venous pulse, to auscultatory signs between the apex beat and the left sternal border, to the $\mathbf{P}$ wave of the electrocardiogram, and to the right atrium, pulmonary artery, and lung fields in the radiograph.

Cardiac Catheterization. Right heart catheterization was performed in all cases with suspected organic tricuspid disease. Cardiac outputs at rest and on standardized exercise using a bicycle ergometer designed in our laboratory (Ramsay, 1958) were measured by the Fick principle, oxygen consumption being measured by Tissot spirometer and Scholander gas analysis, and oxygen content by Brinkman hæmoreflector. Three minutes were allowed after the start of exercise for development of a steady state.

There is no doubt that the most reliable method of recording valve gradients is by means of two catheters or a single double-lumen catheter, recording simultaneous pressures in the right ventricle and right atrium. The dynamic response characteristics of our pressure measuring systems were not at first adequate using double-lumen catheters, and, therefore, withdrawal records across the valve were taken during the periods of voluntary apncea. Diagrams were then constructed in which the right atrial and right ventricular pressures were superimposed during cycles of equal length. Fig. 1 shows a normal subject and a patient with tricuspid stenosis. In the normal subject and in 3 patients with tricuspid stenosis the method was checked by measuring simultaneous pressures through two catheters; the result was identical with the constructed diagram.

The valve area was calculated according to the Gorlin formula (Gorlin and Gorlin, 1951) for the tricuspid valve, i.e.

$$
\text { T.V.A. }=\frac{\text { C.O. }}{\text { D.F.P. } \times 0 \cdot 7 \times 44 \cdot 5 \sqrt{\text { RAm-RVmd }}}
$$

Where T.V.A. $=$ tricuspid valve area in $\mathrm{cm}^{2}$; C.O. $=$ cardiac output $(\mathrm{ml} . / \mathrm{min}$.$) ; D.F.P. =$ diastolic filling period (sec./min.); RAm = right atrial mean pressure $(\mathrm{mm} . \mathrm{Hg})$; and $\mathrm{RVmd}=$ right ventricular mean diastolic pressure $(\mathrm{mm} . \mathrm{Hg})$. 


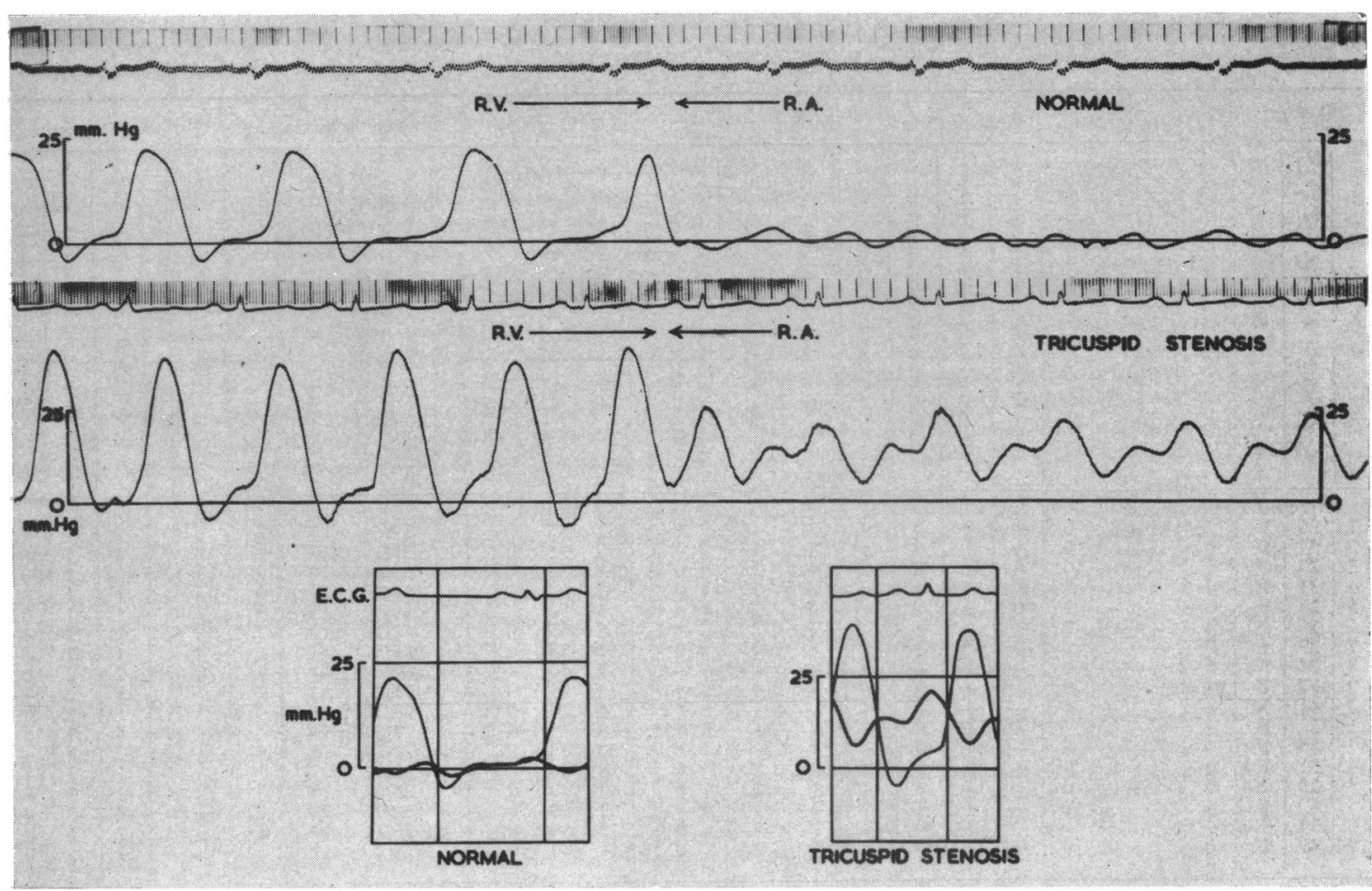

FIG. 1.-Catheter pressure recordings during withdrawal from right ventricle to right atrium, a normal subject and a patient with tricuspid stenosis. Below, diagrams constructed by superimposition of pressure records.

Operation. The operations were performed by the same surgeon (Andrew Logan). The size of the valves was graded by him with reference to the index finger according to the following scheme, the criteria being the same for the mitral and tricuspid valves:

Grade 1: Valve admits no part or only the extreme tip of the index finger.

Grade 2: Valve admits terminal half of the nail of the index finger.

Grade 3: Valve admits terminal phalanx of the index finger (diam. about $1.5 \mathrm{~cm}$.).

Grade 4: Valve admits phalanx of the index finger (diam. about $2 \mathrm{~cm}$.).

Grade 5: Valve admits proximal phalanx (diam. about $2.5 \mathrm{~cm}$.).

In all patients, mitral valvotomy was carried out first and then the tricuspid valve was explored. Valvotomy was usually performed using a mechanical dilator introduced through the ventricular wall (Logan and Turner, 1959).

\section{Clinical Features}

The 17 patients submitted to both tricuspid and mitral valvotomy and the two autopsy cases have been arranged according to the severity of tricuspid stenosis found. Table IA and B shows, in addition to the size of each valve, the features of the jugular venous pulse, the auscultatory findings with reference to the tricuspid valve, and relevant abnormalities of the electrocardiogram and chest radiograph. Table IC shows the same data for the 5 patients with dominant tricuspid incompetence.

Symptoms. In the presence of mitral stenosis no distinction as regards symptoms could be made between patients with mild and patients with severe tricuspid stenosis. All complained. of significant breathlessness on exertion; 9 gave a history of œdema, but the rest, despite severe 
TABLE I

Clinical and Investigative Data

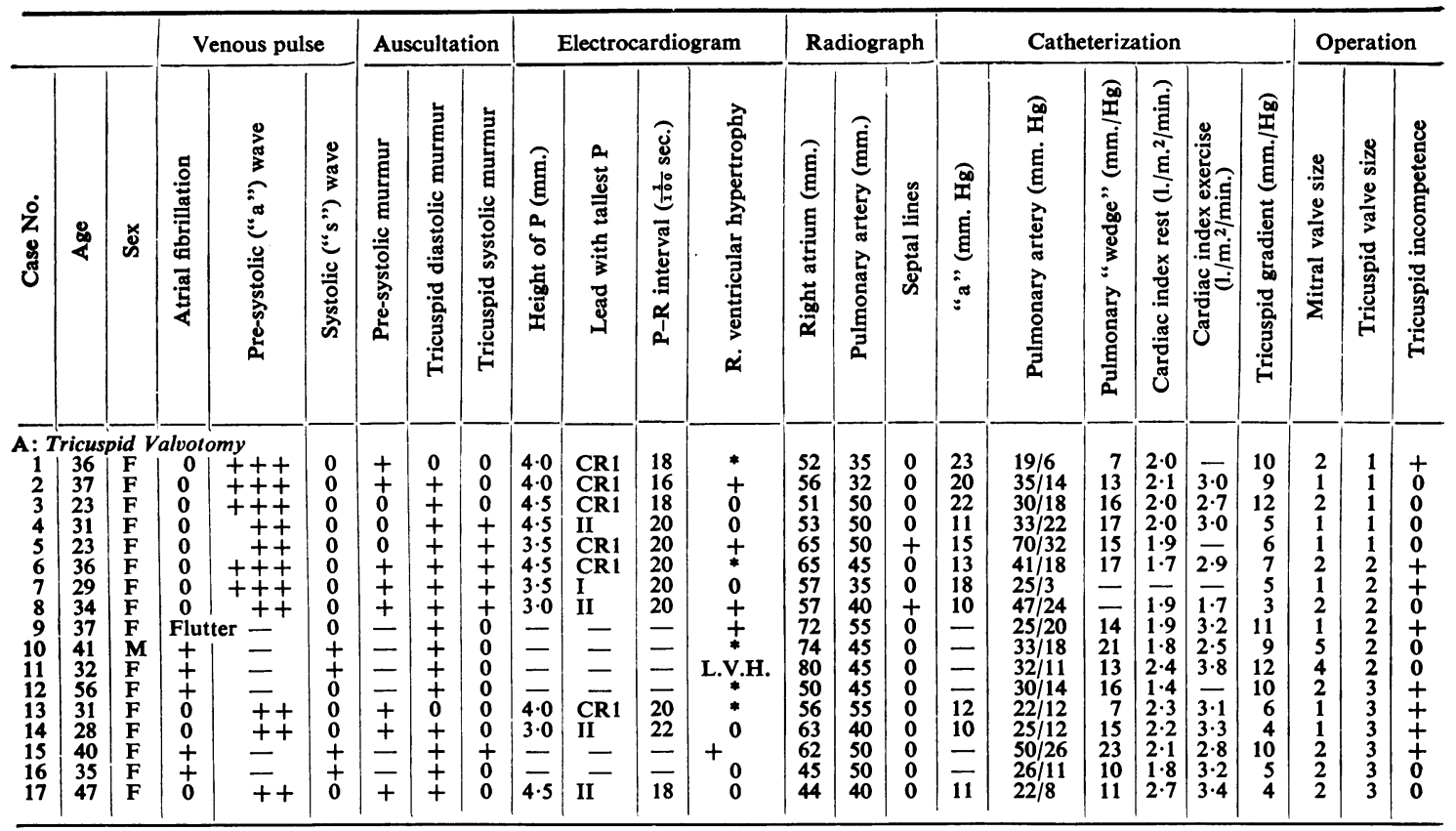

B: Post-mortem Cases of Tricuspid Stenosis

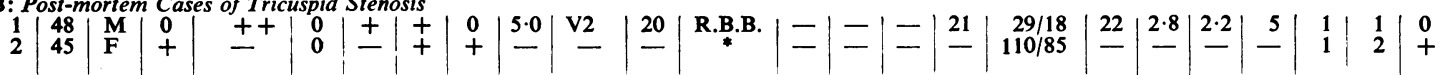

C: Predominant Tricuspid Incompetence

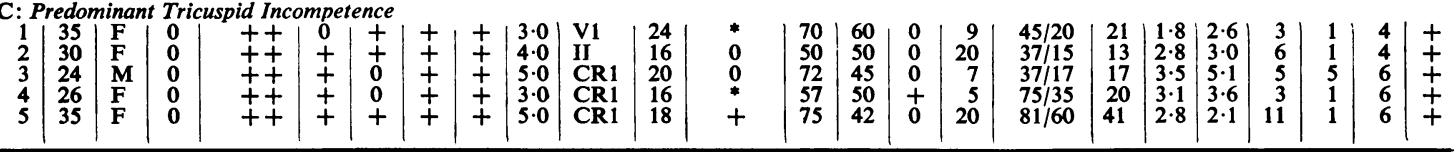

* Incomplete right bundle-branch block.

tricuspid stenosis, did not; 2 had had attacks of paroxysmal nocturnal dyspnoea. The "classical" pict ure of œdema, ascites, and cyanosis was not present in any case.

Jugular Venous Pulse. Four patients had themselves observed visible pulsation in the neck, particularly on exercise, and 5 noted a feeling of congestion in the neck and epigastric discomfort on exercise: in three, this amounted to definite hepatic pain on exertion. However, these were the only symptoms pointing directly to tricuspid valvular disease.

The characteristic flicking presystolic pulsation in the superficial jugular veins at the root of the neck was present in 8 of the 11 patients with severe stenosis who were in sinus rhythm. In 3 , in whom the degree of stenosis was only moderately severe, selective prominence of the "a" wave was present, which, however, lacked the flicking appearance of more severe stenosis.

In addition to the 17 submitted to valvotomy and the 2 who came to autopsy, there were 5 patients (Table IC) in whom a large presystolic "a" wave was accompanied by a visible though lesser systolic wave, the appearance being that of a double pulse for each cardiac cycle. There was in each case a tricuspid diastolic murmur and a diastolic gradient across the tricuspid valve of 3-11 mm. Each of these had exploration of the tricuspid valve immediately after mitral valvotomy and was found to have relatively mild tricuspid stenosis with dominant regurgitation.

In the 7 patients with atrial fibrillation or flutter the systolic wave was prominent and followed by a slow "y" descent. One patient who developed fibrillation some months after operation lost the 
TABLE II

Height of P WaVe in 12 Patients in Sinus Rhythm with Severe Tricuspid Stenosis

\begin{tabular}{l|c|c|c|c}
\hline \multirow{2}{*}{ Lead } & \multicolumn{4}{|c}{ P waves (mm.) } \\
\cline { 2 - 5 } & $<2 \cdot 0$ & $2-2 \cdot 9$ & $3-3.9$ & $4-4.9$ \\
\hline II & 1 & 2 & 7 & 2 \\
CR1 & 0 & 1 & 6 & 5 \\
VI & 3 & 3 & 5 & 1 \\
\hline
\end{tabular}

TABLE III

Chest Radiograph in 17 Patients Operated on for SeVere Tricuspid Stenosis

\begin{tabular}{c|c|c|c|c|c|c|c}
\hline $\begin{array}{c}\text { Cardiothoracic } \\
\text { ratio (\%) }\end{array}$ & $\begin{array}{c}\text { Number of } \\
\text { patients }\end{array}$ & $\begin{array}{c}\text { Right atrial } \\
\text { size (mm.) }\end{array}$ & $\begin{array}{c}\text { Number of } \\
\text { patients }\end{array}$ & $\begin{array}{c}\text { Pulmonary } \\
\text { artery size } \\
\text { (mm.) }\end{array}$ & $\begin{array}{c}\text { Number of } \\
\text { patients }\end{array}$ & Septal lines & $\begin{array}{c}\text { Number of } \\
\text { patients }\end{array}$ \\
\hline$<55$ & 3 & $<55$ & 6 & $<45$ & 6 & None & 15 \\
$55-59$ & 6 & $55-59$ & 4 & $45-49$ & 4 & Slight & 1 \\
$60-64$ & 7 & $60-64$ & 2 & $50-54$ & 5 & Moderate & 1 \\
$65+$ & 1 & $65+$ & 5 & $55+$ & 2 & Gross & 0 \\
\hline Total & 17 & & 17 & & 17 & & 17 \\
\hline
\end{tabular}

"a" wave and developed obvious systolic pulsation. A right ventricular impulse was palpable in 9 of the 19 patients with severe tricuspid stenosis. Pulsation in the liver synchronous with the presystolic venous wave could be felt in 6 patients.

Auscultation. A diastolic murmur which could be clearly distinguished from that of mitral stenosis was heard in all patients. In those with sinus rhythm it was usually loudest in presystole and was best heard at the left sternal border. In patients with atrial fibrillation the tricuspid murmur was loudest in mid-diastole and was usually short and rumbling. In 13 patients the diastolic murmurs convincingly increased in intensity on deep inspiration, and deep expiration often abolished them for one or two beats. A tricuspid systolic murmur was also heard in 8 patients. Tricuspid diastolic murmurs, indistinguishable in timing, intensity, length, and quality from those of tricuspid stenosis, were audible also in the group of patients who proved to have dominant tricuspid incompetence (Table IC).

Electrocardiography. Particular attention was paid to the $\mathbf{P}$ waves, to the $\mathbf{P}-\mathbf{R}$ interval, and to evidence of right ventricular hypertrophy. It was noteworthy that a large proportion of the patients were in sinus rhythm, there being only 3 with atrial fibrillation and 1 with flutter. Peaked $P$ waves greater than $3.0 \mathrm{~mm}$. in height were present in all patients in sinus rhythm and in 8 exceeded $4 \mathrm{~mm}$. (Table I): they were best seen in lead CR1 (Table II). In several cases it was this that first led to a consideration of tricuspid stenosis and to more careful auscultation. The P-R interval was equal to or greater than $0.20 \mathrm{sec}$. in 8 patients. Electrocardiographic signs of right ventricular hypertrophy were present in 11 patients, including some with the most severe degrees of tricuspid stenosis. The criteria for right ventricular hypertrophy were those of Fraser and Turner (1955), and were established on the first 250 cases of this series.

Radiography. Particular attention was paid to four features of the postero-anterior radiograph (Table III). The cardiothoracic ratio gives an index of over-all cardiac enlargement but was of no special value in the present context, being influenced by enlargement of three different chambers, the right atrium, the right ventricle, and the left ventricle, each of which may be affected in varying degree by valvular stenosis or incompetence or by myocardial damage. 

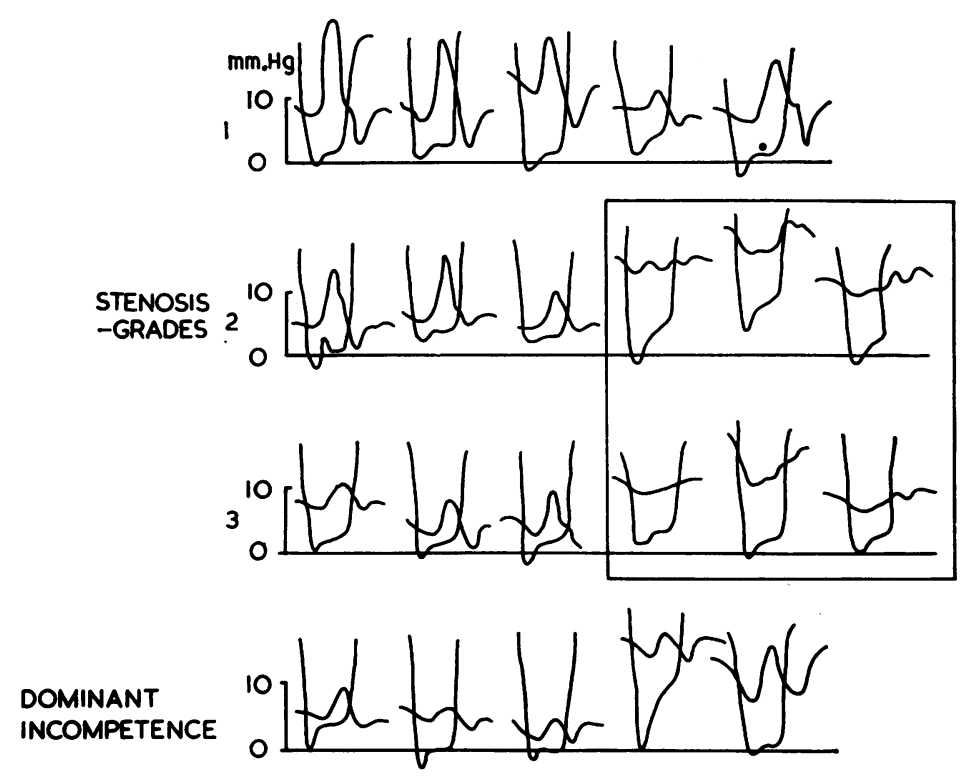

FIG. 2.-Tricuspid valve gradients in diastole in 17 patients with tricuspid stenosis and 5 patients with organic tricuspid incompetence. Atrial fibrillation was present in the 6 patients enclosed in the square.

(a) Enlargement of the right atrium as judged by prominence of the right heart border extending more than $50 \mathrm{~mm}$. from the mid line was present in all but 2 patients. However, the degree of enlargement bore no relation to that of tricuspid stenosis and occurred also in patients with dominant tricuspid incompetence, and, as will be discussed, in those with rheumatic heart disease who had no tricuspid valvular disease.

(b) Enlargement of the pulmonary artery, and its two main branches, associated with pulmonary arterial hypertension, occurred in 10 out of the 17 patients with severe tricuspid stenosis: one of these also had rheumatic pulmonary stenosis.

(c) Transverse septal lines from lymphatic distension are usually most obvious in the costophrenic angle and were associated with pulmonary venous hypertension. It is noteworthy that they were present in two patients despite severe tricuspid stenosis. In each instance there was also severe mitral stenosis.

Cardiac Catheterization. The gradients obtained by catheter withdrawal records across the tricuspid valve are shown in Fig. 2. The data are analysed in Table IV with the patients grouped in order of severity of the tricuspid stenosis.

Four pressure gradients were measured: (1) in early diastole; (2) in late diastole, at the peak of the "a" wave in cases with sinus rhythm; (3) the mean gradient throughout diastole; and (4) the maximum gradient.

The mean gradient throughout the diastolic filling period, obtained by integration or planimetry, is clearly to be preferred since it is less influenced by artefact and by individual variations in pulse wave contour.

In sinus rhythm the early gradient approximated to the mean gradient and the maximum gradient usually corresponded with the "a" wave. All patients with severe stenosis in sinus rhythm had a dominant "a" wave and a mean gradient greater than $5 \mathrm{~mm}$. $\mathrm{Hg}$, except one who exhibited only a late gradient of $5 \mathrm{~mm}$. and an exceptionally low cardiac output. The striking fact emerges that if tricuspid regurgitation is also present considerable gradients may exist in the presence of relatively mild tricuspid stenosis. The features of this type of organic tricuspid incompetence which may mimic tricuspid stenosis will be discussed later. 
TABLE IV

Tricuspid VAlVe Gradients

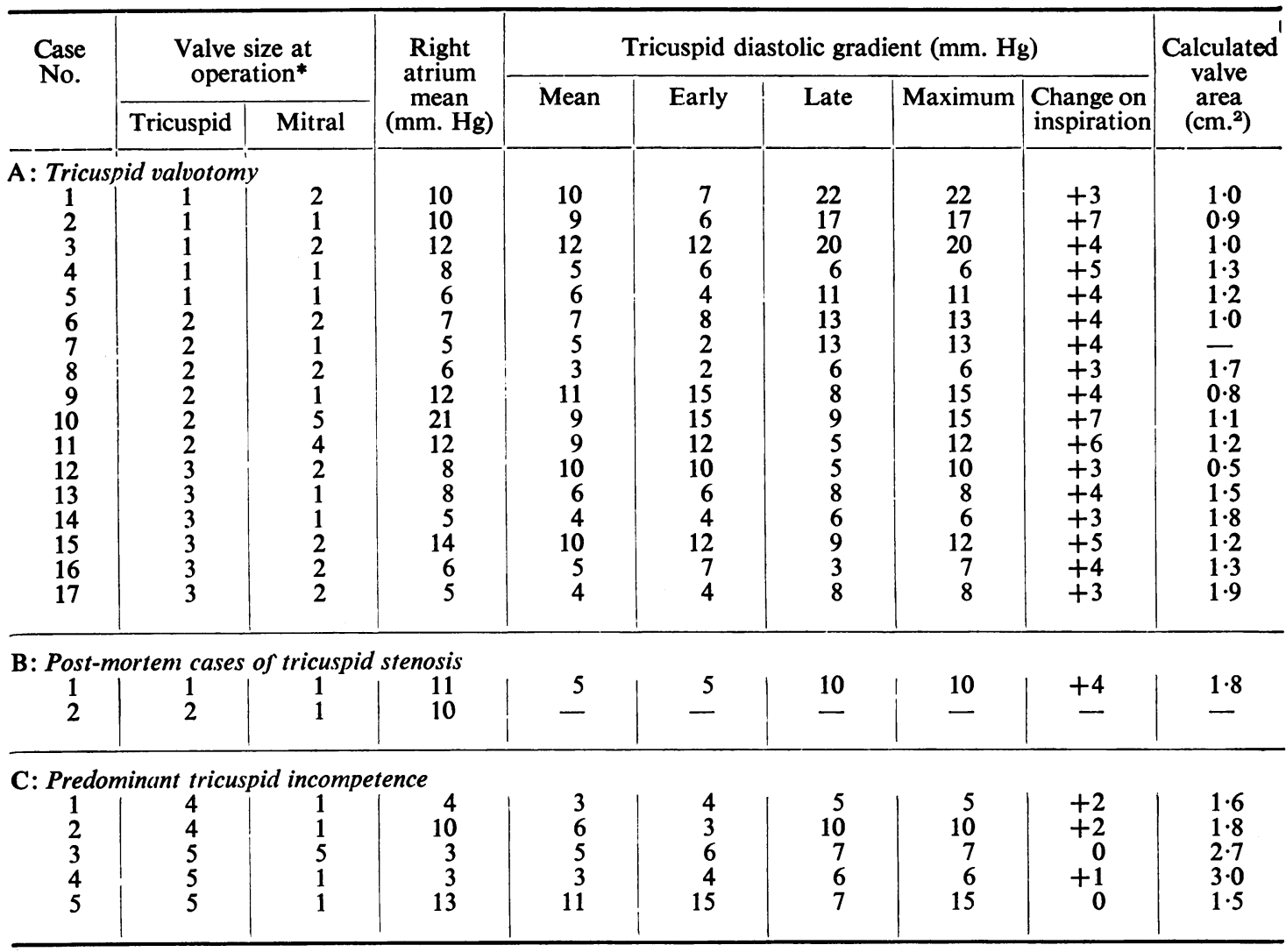

* Grading as on p. 357

When atrial fibrillation or flutter was present the gradient across the valve in diastole was large in relation to the degree of stenosis, and in addition, there was also a predominant systolic wave both in the right atrium and clinically in the jugular pulse despite the presence of severe tricuspid stenosis. The gradient was maximal in early diastole.

Grouped data for mean resting right atrial and pulmonary arterial pressures, cardiac index, and pulmonary vascular resistance at rest and on exercise are shown in Table V. The cardiac output was considerably reduced below normal standards in all patients both at rest and on exercise ( see Fig. 13).

TABLE V

Hæmodynamic Data (Severe Tricuspid Stenosis-19 Patients)

\begin{tabular}{|c|c|c|c|c|c|c|c|c|c|}
\hline \multicolumn{4}{|c|}{ Mean pressure } & \multirow{2}{*}{$\begin{array}{c}\text { Cardiac } \\
\text { index } \\
\left(1 . / \mathrm{m} .^{2} / \mathrm{min} .\right)\end{array}$} & \multicolumn{2}{|c|}{ No. of cases } & \multirow{2}{*}{$\begin{array}{l}\text { Pulmonary } \\
\text { vascular } \\
\text { resistance } \\
\text { (dynes-sec-. } \\
\left.\text { cm. }{ }^{-5}\right)\end{array}$} & \multicolumn{2}{|c|}{ No. of cases } \\
\hline $\begin{array}{c}\text { Right } \\
\text { atrium } \\
(\mathrm{mm} . \mathrm{Hg})\end{array}$ & $\begin{array}{l}\text { No. of } \\
\text { cases }\end{array}$ & $\begin{array}{c}\text { Pulmonary } \\
\text { artery } \\
(\mathrm{mm} . \mathrm{Hg})\end{array}$ & $\begin{array}{l}\text { No. of } \\
\text { cases }\end{array}$ & & Rest & Exercise & & Rest & Exercise \\
\hline $\begin{array}{c}<6 \\
6-11 \\
12-17 \\
18+\end{array}$ & $\begin{array}{r}2 \\
11 \\
4 \\
1\end{array}$ & $\begin{array}{c}<20 \\
20-29 \\
30-39 \\
40+\end{array}$ & $\begin{array}{l}7 \\
8 \\
2 \\
2\end{array}$ & $\begin{array}{c}<2 \\
2-2 \cdot 5 \\
2 \cdot 5-3 \cdot 0 \\
3+\end{array}$ & $\begin{array}{l}7 \\
8 \\
2 \\
0\end{array}$ & $\begin{array}{l}1 \\
2 \\
6 \\
5\end{array}$ & $\begin{array}{c}<200 \\
200-400 \\
400-600 \\
600+\end{array}$ & $\begin{array}{l}9 \\
6 \\
0 \\
1\end{array}$ & $\begin{array}{r}12 \\
1 \\
0 \\
0\end{array}$ \\
\hline
\end{tabular}


Pulmonary hypertension (mean pressure $>20 \mathrm{~mm}$. $\mathrm{Hg}$ ) was present in 12 of the 19 patients but was severe in only 2 . The pulmonary vascular resistance was greatly increased at rest in 1 patient and slightly increased in a further 6 . On exercise the pulmonary vascular resistance fell in 8 of the 13 patients in whom it was measured, and was unaltered in a further 3. Right atrial mean pressure was raised moderately in 11 and severely in 5 patients, the last all having arrhythmia.

TABLE VI

Tricuspid Valvotomy (17 Patients)-Changes After Operation

\begin{tabular}{|c|c|c|c|c|c|c|c|c|}
\hline \multirow{2}{*}{$\begin{array}{l}\text { Case } \\
\text { No. }\end{array}$} & \multirow{2}{*}{$\begin{array}{l}\text { Follow-up } \\
(\mathrm{yr} .)\end{array}$} & \multirow{2}{*}{$\begin{array}{l}\text { Subjective } \\
\text { result }\end{array}$} & \multicolumn{2}{|c|}{ Venous pulse waves } & \multicolumn{2}{|c|}{ Tricuspid murmurs } & \multirow{2}{*}{$\begin{array}{l}P \text { wave } \\
\text { change }\end{array}$} & \multirow{2}{*}{$\begin{array}{l}\text { Change in } \\
\text { right atrial } \\
\text { size (mm.) }\end{array}$} \\
\hline & & & $\begin{array}{c}\text { Pre- } \\
\text { systolic }\end{array}$ & Systolic & Diastolic & Systolic & & \\
\hline $\begin{array}{r}1 \\
2 \\
3 \\
4 \\
5 \\
6 \\
7 \\
8 \\
9 \\
10 \\
11 \\
12 \\
13 \\
14 \\
15 \\
16 \\
17\end{array}$ & \begin{tabular}{c|}
6 \\
Operativ \\
3 \\
2 \\
2 \\
$8 / 12$ \\
2 \\
6 \\
Operativ \\
3 \\
Operativ \\
1 \\
3 \\
2 \\
6 \\
1 \\
1
\end{tabular} & $\begin{array}{l}\text { Good } \\
\text { e death } \\
\text { Good } \\
\text { Good } \\
\text { Good } \\
\text { Died } \\
\text { Good } \\
\text { Good } \\
\text { e death } \\
\text { Died } \\
\text { e death } \\
\text { Good } \\
\text { Good } \\
\text { Good } \\
\text { Good } \\
\text { Fair } \\
\text { Good }\end{array}$ & $\begin{array}{c}\text { Decrease } \\
- \\
\text { Decrease } \\
\text { Decrease } \\
\text { Decrease } \\
0 \\
\text { Decrease } \\
\text { Decrease } \\
\bar{Z} \\
\bar{Z} \\
\text { Decrease } \\
\text { Decrease } \\
\text { - } \\
\text { Decrease }\end{array}$ & $\begin{array}{c}\frac{0}{0} \\
0 \\
0 \\
\text { Increase } \\
0 \\
0 \\
\frac{0}{0} \\
\frac{0}{0} \\
\text { Increase } \\
\text { Increase } \\
0 \\
0 \\
0\end{array}$ & 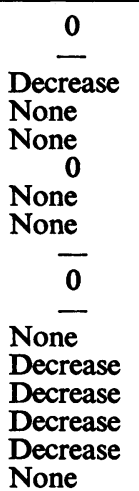 & $\begin{array}{c}\frac{0}{0} \\
0 \\
0 \\
\text { Increase } \\
\overline{0} \\
\frac{0}{0} \\
\frac{0}{0} \\
\text { Increase } \\
\text { Increase } \\
0 \\
0 \\
0\end{array}$ & $\begin{array}{c}\frac{0}{-} \\
\text { Decrease } \\
\text { Decrease } \\
\text { Decrease } \\
0 \\
\frac{1}{2} \\
\text { Decrease } \\
\bar{z} \\
\overline{-} \\
\text { Decrease } \\
\text { Decrease } \\
\text { 二 } \\
\text { Decrease }\end{array}$ & $\begin{array}{l}-12 \\
-5 \\
+5 \\
+6 \\
+12 \\
+7 \\
+4 \\
0 \\
-+6 \\
+0 \\
0 \\
-3 \\
+3 \\
-6 \\
-4\end{array}$ \\
\hline
\end{tabular}

$0=$ no change; $-=$ not applicable.

Surgical Treatment. All but 2 of the 17 patients also had tight mitral stenosis as judged by the criteria already given, and mitral valvotomy was also carried out. In one patient an error was made as regards the degree of stenosis at the mitral valve. Eleven patients had tight tricuspid stenosis $\left(<1 \mathrm{~cm}^{2}\right)$, and 6 moderately tight stenosis $\left(1-1.5 \mathrm{~cm} .{ }^{2}\right)$. In all the patients the degree of stenosis was considered sufficient to warrant valvotomy. In 4 the degree of tricuspid stenosis was greater than that of mitral stenosis. In 5 the two valves were equally narrowed, and in 8 the degree of mitral stenosis was greater than that at the tricuspid valve. Palpable tricuspid regurgitation was frequently found, and was present in 8 patients.

Three patients died during the operation, but death was not considered to be due to the tricuspid valvotomy. One died from chest hæmorrhage two hours after operation, and the second from circulatory failure in a severely disabled patient with mitral, tricuspid, and pulmonary stenosis, each of severe degree and for each of which valvotomy was carried out. She was found subsequently also to have cardiac hepatic cirrhosis, a condition which later experience has shown often to be associated with post-operative circulatory failure and, which, if detected, we now consider to be a contraindication to surgical treatment. The third was a patient, previously treated by a second valvotomy for mitral restenosis, who had a third operation ten years after the first by the open-heart method for the relief of aortic and tricuspid stenosis. Owing to a technical mishap there was a period of undue hypotension and she sustained irreversible cerebral damage. Traumatic, i.e. operative valvular incompetence of significant degree occurred in one patient.

Changes Following Operation. The longest period of follow-up to date is seven years and the shortest is 18 months (Table VI). One patient deteriorated after operation on account of traumatic 
incompetence of both mitral and tricuspid valves: she died twelve months later after attempted repair of both defects by open-heart surgery. Another who had severe tricuspid stenosis relieved at operation, with relatively mild mitral stenosis, was improved for two years, but then deteriorated with cardiac failure and died one year later: he had a long history (17 years) of breathlessness, atrial fibrillation, a large heart, venous congestion, and hepatomegaly with involvement of tricuspid, mitral, and aortic valves.

Of the remaining 12 survivors of the operation, 10 have remained well with excellent symptomatic relief, little or no disability from breathlessness, and no signs of cardiac failure. One with moderately severe tricuspid stenosis and tight mitral stenosis has had only a fair degree of improvement. The last patient in whom a satisfactory tricuspid valvotomy but relatively inadequate mitral valvotomy was carried out had a better mitral valvotomy performed three and a half years later with a very good result, and has remained well since.

Symptoms. Because of combined mitral and tricuspid valvotomy it is impossible to assess whether subjective improvement is due to one or other or both valves being widened.

Murmurs. Six patients lost the tricuspid diastolic murmur after operation, and in these cases, apart from a slight prominence of the " $a$ " wave in the venous pulse, clinical evidence of tricuspid disease virtually disappeared. The remainder retained a diastolic murmur but of lesser intensity and shorter duration, and in only one patient, followed up for six years, was the intensity more than Grade 2/6: in this patient there was also no electrocardiographic regression, and a flicking "a" wave, though smaller, is still present. Symptomatically she remains well but a repeat catheterization shows that a mild degree of stenosis persists. This was the first tricuspid valvotomy performed in the unit.

In three patients a tricuspid systolic murmur of Grade $2 / 6$ developed after operation and was considered to represent a minor degree of tricuspid regurgitation. They have both had excellent symptomatic results.

Venous Pulse. Regression of the flicking "a" wave in the jugular venous pulse occurred in all patients in sinus rhythm, and in five the venous pulse became virtually normal. In three regression of the "a" wave has been incomplete. A large systolic wave was produced in the patient with traumatic tricuspid incompetence who died. Another, who had a good result from operation, developed atrial fibrillation two years later and, losing the slightly prominent " $a$ " wave, developed a systolic wave instead.

Electrocardiogram. Three of the original 17 patients died at an early stage. Atrial fibrillation prevents comparison of $P$ waves in a further 4 patients. Of the remaining 10, 7 show considerable regression of the tall $P$ waves. Another, followed for two years, has shown only slight regression despite a good valvotomy and relief of symptoms. In this instance there was a mild degree of tricuspid regurgitation shown by a Grade $2 / 6$ systolic murmur and by dye dilution curves.

No regression occurred in two patients: one was the patient in whom gross tricuspid incompetence was produced at operation; and the other is the patient referred to above in whom the valvotomy may have been incomplete.

Radiography. Decrease in the size of the right atrium as judged radiographically occurred in five patients and in only two to any striking extent. The situation is apparently similar to that after mitral valvotomy, when decrease in left atrial size is unusual. It reflects the fact, discussed later, that chamber size is not closely related to the pressure within.

Catheterization. Post-operative catheterization was not done routinely in patients who were symptomatically well, since there was no reasonable doubt that the stenosed tricuspid valves were opened widely at operation. Five patients, however, were catheterized after operation in order to establish objectively what was achieved by valvotomy. All had tight tricuspid stenosis at operation, and subsequent catheterization showed considerable reduction of the valve gradient and reduction in the " $a$ " wave of the right atrial pulse (Fig. 3). Indicator dilution studies in one patient showed no difference in contour between right ventricular and pulmonary arterial injections, indicating that no significant degree of traumatic incompetence had been produced at operation. 


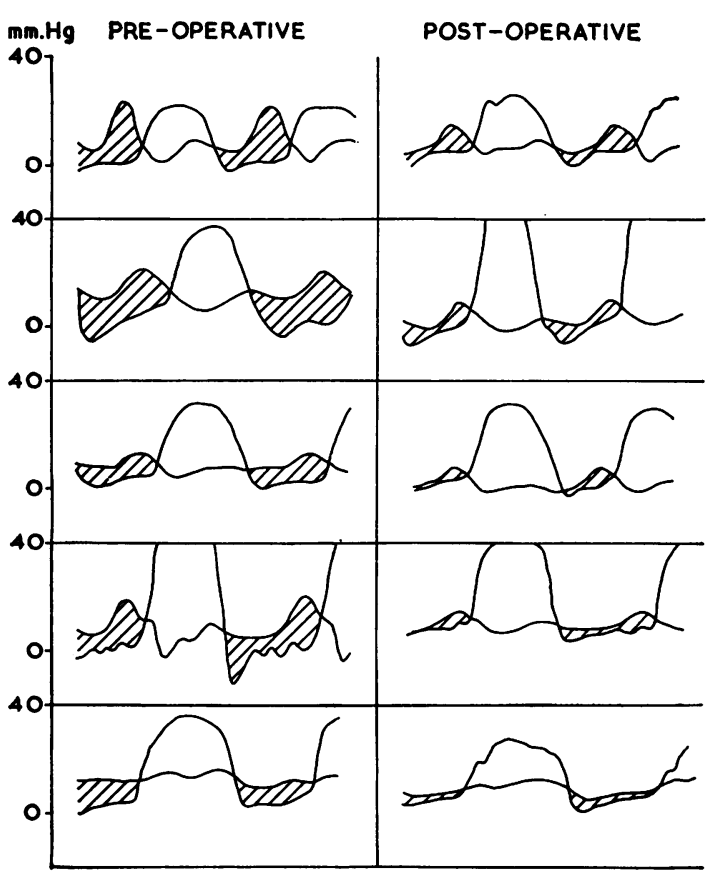

FIG. 3.-Tricuspid valve gradients (shaded areas) before and after tricuspid valvotomy in 5 patients with severe tricuspid stenosis.

\section{Discussion}

Jugular Venous Pulse. Since in our experience diagnostic abnormalities indicating tricuspid valve disease have rarely been observed by the referring physician, it is worth emphasizing that it should be the invariable rule during clinical examination not only to note the jugular venous pressure but also the characteristics of the jugular venous pulsation. In sinus rhythm the most reliable sign of important tricuspid stenosis was a characteristic flicking " $a$ " wave best seen in the external jugular veins at the root of the neck. This pulsation is frequently much more prominent on one side of the neck than the other and may on this account be missed if only one side is examined. Normally a small "a" wave may be present with the patient supine but in tricuspid stenosis an " $a$ " wave will be observed with the patient sitting up, although it is not always very striking. By contrast, the systolic wave of tricuspid regurgitation is usually best seen in the deep veins and is often overlooked.

Although a somewhat prominent "a"

wave is occasionally seen in patients with mitral stenosis who have severe pulmonary hypertension, especially if tricuspid incompetence is present, in our experience conspicuous flicking "a" waves are pathognomonic of tricuspid stenosis and denote that the obstruction is severe. Contrary to what is often considered, this wave can readily be appreciated by the finger and is not infrequently mistaken for an arterial pulsation. An experienced observer will recognize the difference by inspection, but in cases of doubt differentiation is assisted by observing the effect on the venous pressure and pulsations of respiration, posture, and pressure over the abdomen, none of which affect the arterial wave.

Timing of the venous pulse may be difficult. The " $a$ " wave in the neck is not, as often assumed, synchronous with right atrial contraction. Measurements in 6 of our patients have shown that transmission of the right atrial wave to the jugular vein occupies $0.07-0 \cdot 10 \mathrm{sec}$. Hence a wave that is caused by atrial contraction may appear to be almost synchronous with the first heart sound (Fig. 4). The presystolic "a" wave occurs just before, but may appear to be almost synchronous with, the carotid arterial pulse, whereas the systolic ("s") wave of tricuspid incompetence, although occurring earlier than the physiological " $v$ " wave, follows the carotid pulsation. If the mean venous pressure is moderately raised and two distinct waves are seen with the patient reclining at $45^{\circ}$, then even if the " $a$ " wave is larger than the systolic wave, severe tricuspid stenosis is unlikely to be present and in most cases there is dominant tricuspid incompetence.

If atrial fibrillation is present the diagnosis of tricuspid stenosis from examination of the neck veins is not possible owing to absence of the presystolic " $a$ " wave which is, of course, dependent on atrial contraction. A slow " $y$ " descent, i.e. following the positive " $v$ " wave, may be difficult to appreciate clinically. However, the presence of a tricuspid diastolic murmur in a patient with atrial fibrillation and raised venous pressure always raises the strong possibility of significant tricuspid stenosis being present, and catheterization is advisable in order to assess its degree. 


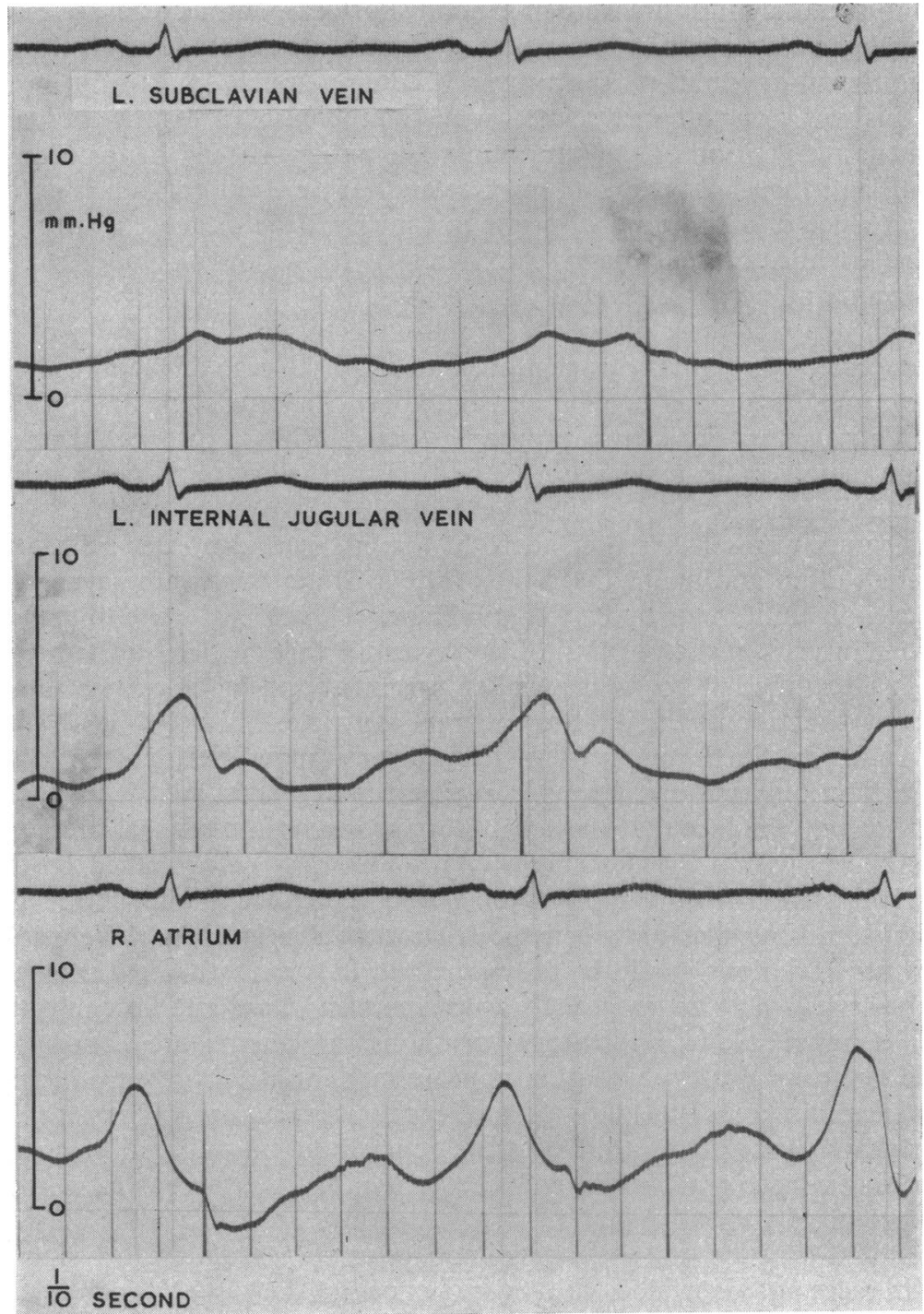

FIG. 4.-Relation between electrocardiogram and pressure pulse in right atrium, internal jugular vein, and subclavian vein in a patient with mitral stenosis, showing progressive attenuation and delay of " $a$ " wave distal to the heart.

Two of our patients exemplified the observation of Reale et al. (1956) that in tricuspid stenosis with atrial fibrillation the presence of a considerable systolic wave in the venous pulse does not necessarily imply gross tricuspid incompetence, and may result from only a small regurgitant jet.

Auscultation. In this series the most obvious auscultatory sign of tricuspid stenosis in patients with sinus rhythm was a clear presystolic murmur synchronous with the " $a$ " wave. The murmur usually lacked the apparent crescendo quality of a mitral presystolic murmur, probably because of the unaccentuated first sound. In our experience a clear separate presystolic murmur is not a common finding in patients who have severe mitral stenosis, and if such a murmur is well heard internal to the apex and towards the left sternal border the question of a tricuspid origin should always be considered. 
Tricuspid mid-diastolic murmurs were in general shorter than the corresponding mitral diastolic murmur, presumably because of the lesser pressure gradients across the valve. In all cases a respiratory variation was apparent, the murmur becoming much louder during inspiration. At catheterization this was seen to be associated with the increased pressure gradient. Technique is all important in the recognition of this murmur. The patient should be instructed to take a long, slow, deep breath and then hold it in full inspiration. If careful attention is paid throughout this manœuvre the presence of a tricuspid diastolic murmur will be clearly apparent. A deep breath increases the negative intrathoracic pressure and thereby the inflow of blood from the great vessels into the right atrium and across the valve.

As with mitral stenosis, there is no close relation between the duration of the mid-diastolic murmur and the degree of valvular obstruction, but, as in the case of the mitral valve, a short and inconspicuous murmur is unlikely to be associated with severe stenosis of the tricuspid valve. Tricuspid diastolic murmurs are heard in organic tricuspid incompetence: the presence of such a murmur therefore merely indicates disease of the tricuspid valve, and does not in itself reveal the type of the valvular defect.

Tricuspid murmurs were always best heard at the left sternal border a little to the left of the midline. Although often audible to the right of the sternum they were never maximal in the socalled tricuspid area, a point made by Perloff and Harvey (1960). The site to the left of the sternum is the expected one in view of the position of the tricuspid valve which, in the presence of tricuspid stenosis, is displaced to the left by right atrial enlargement and by clockwise rotation of the heart and of the leftward direction of the jet into the right ventricle.

Respiratory variations in the intensity of tricuspid murmurs merit further discussion. In the normal heart there are only minor changes in right atrial and right ventricular pressure during the respiratory cycle despite the fact that the respiratory swing in intrapleural pressure must be transmitted to all structures within the thoracic cavity. This may be explained by the free inflow of blood into the right atrium from the large veins, and the free communication between the right atrium and ventricle during diastole when the tricuspid valve is open. Were it not for this, the intrapleural pressure variations would be fully apparent in the right heart chambers. If, however, the tricuspid valve is severely narrowed the normal increase in volume flow into the right ventricle with inspiration is impeded and respiratory variations in pressure are abnormally large in that chamber. Little or no respiratory variation appears in right atrial pressure because this chamber is already distended and there is free inflow from the venous reservoirs. The net result is that during inspiration the right ventricular diastolic pressure follows the intrapleural pressure and falls more than normally so that a large gradient is produced across the tricuspid valve. Increased turbulence caused by the more rapid flow through the narrowed orifice accentuates the diastolic murmur.

It is usually stated that the systolic murmur of tricuspid regurgitation becomes louder during inspiration, and in cases not associated with severe stenosis of the valve this can often be appreciated. The probable explanation lies in the normal increased filling of the right ventricle under the influence of the negative swing in intrathoracic pressure and the consequent higher pressure gradient in systole between the right ventricle and right atrium associated with the increased stroke output. It is noteworthy that in patients with cardiac failure and a high venous filling pressure this respiratory variation may not be evident because blood flow is maximal and cannot be increased by inspiration.

It has, however, been our experience in patients with significant tricuspid stenosis that the reverse of the expected pattern usually occurs in that a systolic murmur from associated tricuspid incompetence actually decreases with inspiration and increases with expiration. Under certain circumstances this may be a useful pointer to predominant stenosis or incompetence in the mixed valvular defect. The explanation for this phenomenon presumably rests on the same basis as that for the changes in the diastolic murmur discussed above. When the valve is narrowed the usual increased filling of the right ventricle during inspiration is reduced. Intrathoracic pressure variations are therefore fully transmitted to the right ventricle and the systolic pressure falls on inspiration. Since the right atrial pressure is relatively unaffected the systolic pressure gradient across the tricuspid 
valve is decreased by inspiration and the systolic murmur becomes less prominent. Consequently a change in intensity of a systolic murmur with respiration is not always a reliable method of distinguishing between mitral and tricuspid systolic murmurs as sometimes thought.

Cases of mild tricuspid stenosis occurring in association with mitral stenosis are by no means uncommon and will often be found if sufficient care is taken over auscultation. In our series of 500 consecutive patients treated by mitral valvotomy a tricuspid diastolic murmur was frequently heard. Unfortunately, an accurate estimate of the incidence of such a murmur cannot be given because it is certain that in the early years especially insufficient care was taken specifically to exclude tricuspid valvular disease in each case. Frequently the murmur was only audible during inspiration and could therefore readily be missed. The neck vein pulsations may show only slight prominence of the " $a$ " wave, and such a wave will only be present with sinus rhythm. There may be little or no right atrial enlargement radiographically. In such clinically mild cases the murmur has been accepted as indicating mild tricuspid narrowing without confirmation by catheterization. The incidence of tricuspid stenosis of some degree in patients with severe mitral valvular disease is probably about 5-10 per cent.

A separate opening snap attributable to the tricuspid valve could not be proved but was sometimes suspected: the difficulty lies in the concomitant presence of a clear snap at the left sternal border and produced at the mitral valve.

Electrocardiography. Tall peaked $\mathrm{P}$ waves are not diagnostic of tricuspid stenosis and may also be found in pulmonary stenosis and in severe pulmonary hypertension from any cause. In the setting of rheumatic heart disease they may result from tricuspid incompetence secondary to pulmonary hypertension produced by mitral valvular disease. Probably the relevant factors are hypertrophy and dilatation of the right atrium, resulting from increased pressure work or increased volume work. Increased pressure work may be due to tricuspid stenosis or to right ventricular hypertrophy or failure and increased volume work to tricuspid incompetence.

Tricuspid incompetence may be functional or organic: functional tricuspid incompetence results from right ventricular failure which is usually secondary to pulmonary hypertension, and this itself results from a combination of mitral valvular disease and a secondary increase in the pulmonary vascular resistance due to functional or organic narrowing of the pulmonary arterioles. Organic tricuspid incompetence is usually associated with organic tricuspid stenosis.

The important points to be emphasized are that the detection of tall $\mathbf{P}$ waves in the electrocardiogram should always lead to a careful search for evidence of tricuspid valvular disease, a condition which in fact is often overlooked, and, if found, steps should be taken to exclude tricuspid stenosis of a degree sufficient to require valvotomy. It is also important to know that if tricuspid disease is present tall $\mathbf{P}$ waves may be due to dominant tricuspid incompetence, and this may be secondary to severe mitral stenosis requiring valvotomy.

Occasionally functional tricuspid incompetence may be secondary to severe pulmonary hypertension associated with dominant mitral incompetence or to right ventricular failure secondary to dominant myocardial damage. It is not therefore necessarily associated with severe mitral stenosis. However, it is important to recognize that extreme mitral stenosis may be associated with severe reversible tricuspid incompetence giving rise to a loud apical systolic murmur which does not change on respiration. Such patients may be denied mitral valvotomy owing to a mistaken diagnosis of dominant mitral incompetence.

Tall $\mathbf{P}$ waves in a patient with mitral disease are therefore important to note because this finding always signifies that some complication is present either in the form of tricuspid valvular disease or of pulmonary hypertension or of both conditions. Regression of tall P waves following tricuspid or mitral valvotomy is good evidence of successful surgical treatment.

In Fig. 5 are shown $P$ waves in various leads in patients with severe tricuspid stenosis and in patients with dominant tricuspid incompetence, $P$ waves in CR1 in patients with severe tricuspid stenosis and with dominant mitral incompetence, and also electrocardiograms recorded before and after operation in patients with tricuspid stenosis, pulmonary stenosis and mitral stenosis with pulmonary hypertension to show in each case regression of the pattern of $P$ pulmonale. 


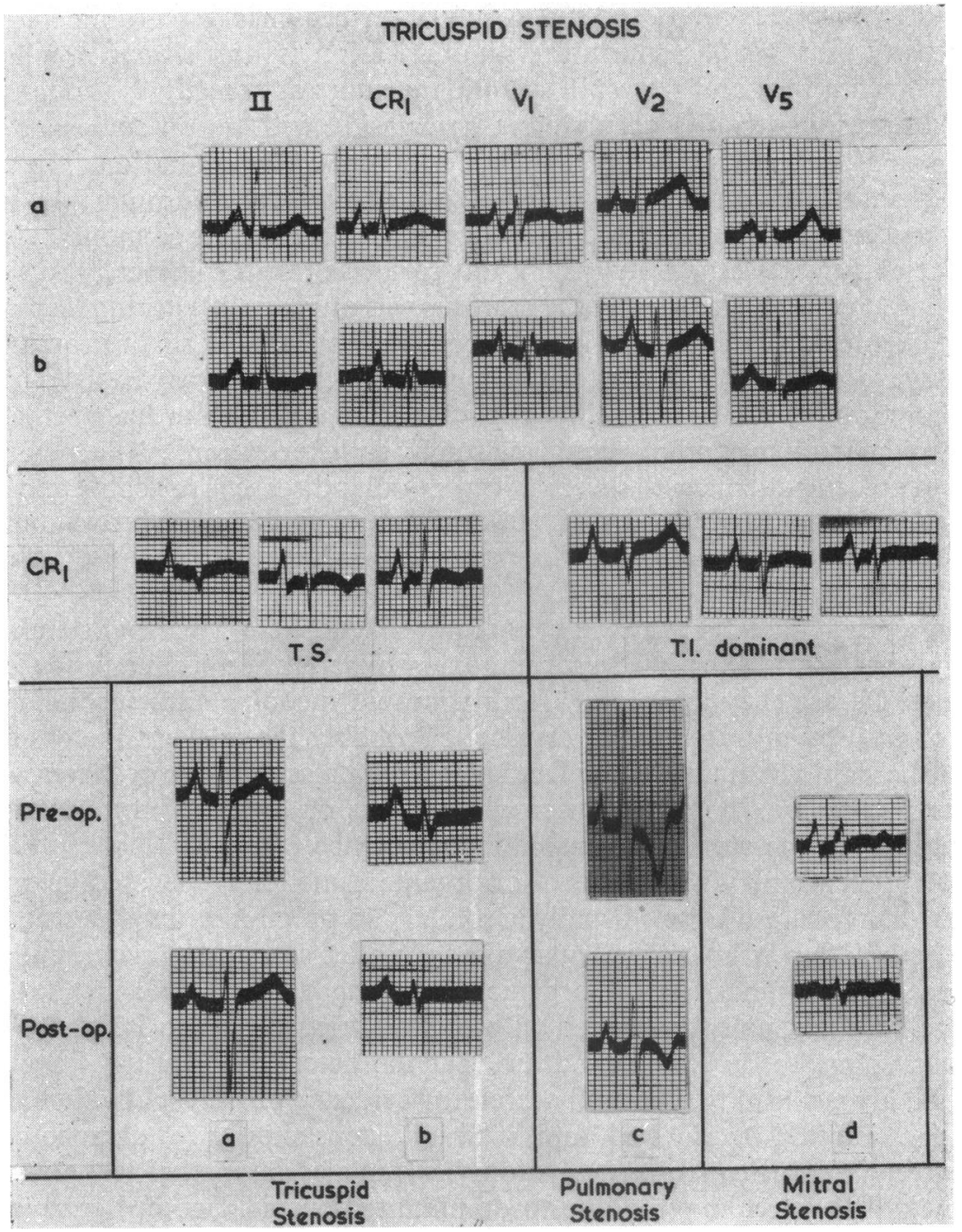

Fig. 5.-Above, $\mathrm{a}$ and $\mathrm{b}, \mathrm{P}$ wave patterns in two patients with severe tricuspid stenosis. Middle, $\mathbf{P}$ wave in lead $\mathrm{CR} 1$ in three patients with severe tricuspid stenosis and three with predominant incompetence. Below, $\mathbf{P}$ waves (lead CR1) in two patients with tricuspid stenosis ( $a$ and $b$ ), one with pulmonary stenosis (c), and one with mitral stenosis with pulmonary hypertension (d), showing in each case regression of $\mathbf{P}$ pulmonale following operation.

The maximum height of $P$ in any lead does not normally exceed $2 \mathrm{~mm}$. Some workers (Leatham, 1950; Thomas and Dejong, 1954) have accepted $2.5 \mathrm{~mm}$. or even $3 \mathrm{~mm}$. as the maximal normal height of $\mathrm{P}$ but Simonson (1961) has stressed the necessity of ignoring extreme stray values for any electrocardiographic item and accepting the 95 per cent distribution in the healthy population as the normal limit. This means the $\mathbf{9 7 . 5}$ per cent limit for the upper range. Hence $\mathbf{P}$ waves taller than $2.0 \mathrm{~mm}$. are probably abnormal. In our experience chest lead CR1, that is between the right arm and the normal V1 position, is usually superior to conventional leads in detecting right atrial hypertrophy.

The amplitude of $\mathbf{P}$ in our series of cases of mitral stenosis was measured in 275 consecutive patients in sinus rhythm who were proved at operation to have severe stenosis. These patients were 
divided into three groups: (1) those with organic tricuspid disease (11); (2) those with a cardiographic pattern of right ventricular hypertrophy (164); and (3) those with neither tricuspid disease nor right ventricular hypertrophy (97).

The results are shown in Table VII divided into these three groups and classified according to the maximum height of $P$ in any lead including CR1: 106 of the 275 cases $(30 \%)$ had $P$ waves exceeding $2 \mathrm{~mm}$. in height and in 69 of them $(25 \%)$ they exceeded $2.5 \mathrm{~mm}$.

TABLE VII

Severe Mitral Stenosis (275 Patients): Maximal Height of P in any Lead

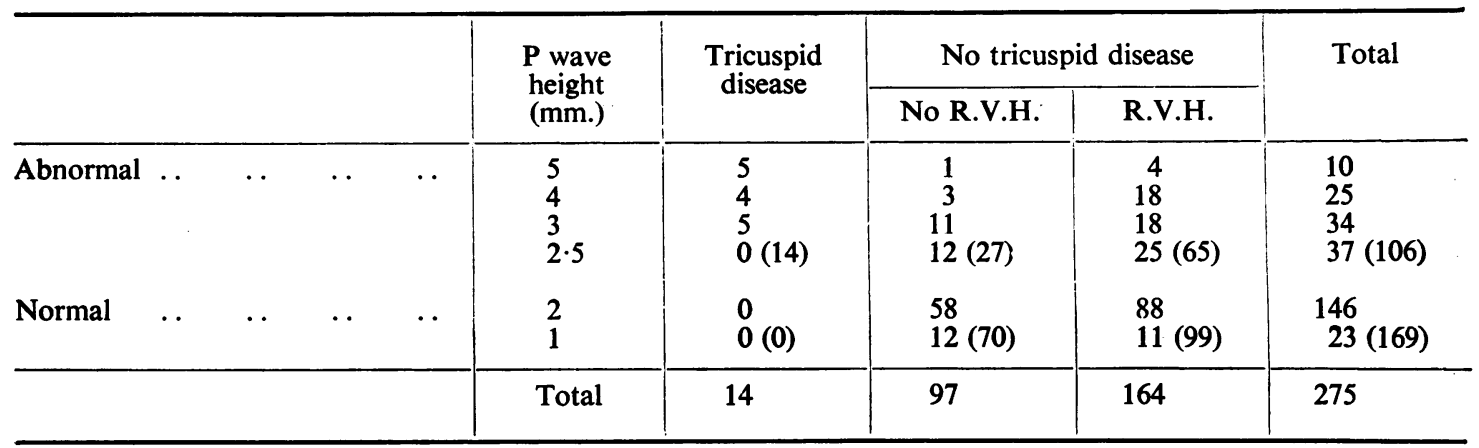

R.V.H. $=$ right ventricular hypertrophy.

All 11 patients in sinus rhythm operated on for tricuspid stenosis had abnormally tall $P$ waves. The best lead for showing this was CR1 in 6, lead II in 4, and lead I in 1 patient. Patients with mild tricuspid stenosis and predominant incompetence may have $P$ waves that are as tall as those with severer stenosis. In addition to clinical observation, this has been proved by hæmodynamic studies and occasionally by exploration of the valve.

Excluding the tricuspid group, the finding that 92 out of a total of 264 cases with mitral stenosis had $P$ waves of $2.5 \mathrm{~mm}$. or more in height is in agreement with the results of a detailed study of $P$ wave abnormalities made by Thomas and Dejong (1954). They found evidence of right atrial hypertrophy in 50 per cent of cases with severe mitral stenosis, commonly in those with pulmonary hypertension.

Of the 164 cases with cardiographic evidence of right ventricular hypertrophy, $75(46 \%)$ had abnormally tall $\mathbf{P}$ waves, and of these large numbers of patients showed regression of $\mathbf{P}$ following mitral valvotomy. There were 55 cases with $P$ waves of $3 \mathrm{~mm}$. or more in any lead: regression after mitral valvotomy occurred in 21 of the 33 cases $(63 \%)$ who remained in sinus rhythm and were available for follow-up a year or more later. The presence of right ventricular hypertrophy affords an explanation for right atrial hypertrophy either from ventricular failure and consequently a raised diastolic filling pressure against which the atrium must contract, or from decreased compliance of the hypertrophied ventricle and hence again increased pressure work for the right atrium or from both factors.

Of the 97 cases with neither tricuspid valve disease nor right ventricular hypertrophy, $27(28 \%)$ had $P$ waves beyond the normal range, though only 4 exceeded $3 \mathrm{~mm}$. in height. It is probable that in many cases there was a degree of right ventricular hypertrophy not reflected in the electrocardiogram. It is well established that owing to the normal dominance of the left over the right ventricle considerable right ventricular hypertrophy may develop before it is evident electrocardiographically. Alternatively, they may have had a degree of tricuspid incompetence that was not recognized clinically.

As regards the best lead for demonstrating right atrial hypertrophy, of 69 patients with $P$ waves exceeding $2.5 \mathrm{~mm}$. in any lead, $34(49 \%)$ showed this best in lead CR1 and $30(44 \%)$ in lead II (Table VIII). 
TABLE VIII

Right Atrial. Hypertrophy ( $>$ >2.5 mm.): Best Electrocardiogram LeAd-(69)

\begin{tabular}{|c|c|c|c|c|c|c|}
\hline \multicolumn{3}{|c|}{ Lead } & No R.V.H. & R.V.H. & Tricuspid disease & All cases \\
\hline $\begin{array}{l}\text { CR1 } \\
\text { II ... } \\
\text { VI } \\
\text { Other }\end{array}$ & $\begin{array}{l}\because \\
\because \\
\ddot{.}\end{array}$ & $\begin{array}{l}\ldots \\
\cdots \\
\cdots \\
\cdots\end{array}$ & $\begin{array}{r}2 \\
12 \\
0 \\
1\end{array}$ & $\begin{array}{r}22 \\
14 \\
3 \\
1\end{array}$ & $\begin{array}{r}10 \\
4 \\
0 \\
0\end{array}$ & $\begin{array}{r}34 \\
30 \\
3 \\
2\end{array}$ \\
\hline Total & .. & .. & 15 & 40 & 14 & 69 \\
\hline
\end{tabular}

There appeared to be a difference between those cases with tall $\mathrm{P}$ waves from tricuspid disease or right ventricular hypertrophy, in which the best lead was generally CR1, and those cases with tall $\mathbf{P}$ waves unexplained by either of these factors. In the latter group a tall and broad P in lead II was not associated with abnormally tall $\mathrm{P}$ waves in the præcordial leads. It is possible that this pattern reflects mainly left atrial hypertrophy.

In summary, whereas $\mathrm{P}$ greater than $2.5 \mathrm{~mm}$. was always present with significant tricuspid stenosis or organic incompetence and frequently when there was cardiographic evidence of right ventricular hypertrophy without tricuspid disease, it was rarely present without either of these conditions, and if greater than $3 \mathrm{~mm}$. almost always signified tricuspid disease.

$P-R$ Interval. Goodwin et al. (1957) and also Reale et al. (1956) have pointed out that in tricuspid stenosis the $P-R$ interval is frequently greater than 0.20 sec., presumably because of right atrial dilatation, and have suggested this as a pointer to the diagnosis. Fig. 6 shows the distribution of the P-R interval in 264 patients with severe mitral but without tricuspid stenosis who were subjected to mitral valvotomy and in 21 patients with proved organic tricuspid disease. The mean interval is somewhat longer in the patients with tricuspid involvement but in the individual patient it is of no help in diagnosis.

Radiography. The radiographic signs generally considered to indicate tricuspid stenosis are enlargement of the right atrium, absolute or relative lack of enlargement of the pulmonary artery and relatively clear lung fields. Several of our patients with tight tricuspid stenosis fulfil all these criteria (Fig. 7), but none is necessarily present in the individual case. The development of these signs will be influenced by the time of onset and by the degree and duration of associated mitral valvular disease in relation to the tricuspid disease. In addition, there may be radiographic signs directly due to mitral or aortic valvular disease. Calcification of the tricuspid valve was not found in any patient, and has not been reported.

Right Atrium. Two of the 17 patients with tight tricuspid stenosis did not show significant enlargement of the right atrium as judged by measurement of the maximal distance of the right heart border from the mid-line in a six-foot postero-anterior film. The other 15 all showed enlargement greater than $55 \mathrm{~mm}$. from the mid-line. Sepulveda and Lukas (1955), from a study of angiograms, concluded that for practical purposes this method was accurate, and a similar method has been recommended by Goodwin et al. (1957).

Fig. 8 shows the apparent size of the right atrium, as judged radiographically, plotted against the mean right atrial pressure in 70 patients with rheumatic heart disease from our clinic. There is a fairly good over-all statistical correlation between size and pressure, but clearly the scatter is so large that factors other than pressure must be involved, and right atrial enlargement is an unreliable sign of tricuspid disease. Presumably the most important factor is rheumatic involvement of the myocardium. Similarly in our experience there is no close correlation between the degree of left atrial enlargement at different ages and in both sexes related to the degree and probably duration of valvular heart disease and to the left atrial pressure gauged by the pulmonary arterial wedge pressure.

Fig. 8 also shows that patients with tricuspid stenosis are not distinguished from others showing 


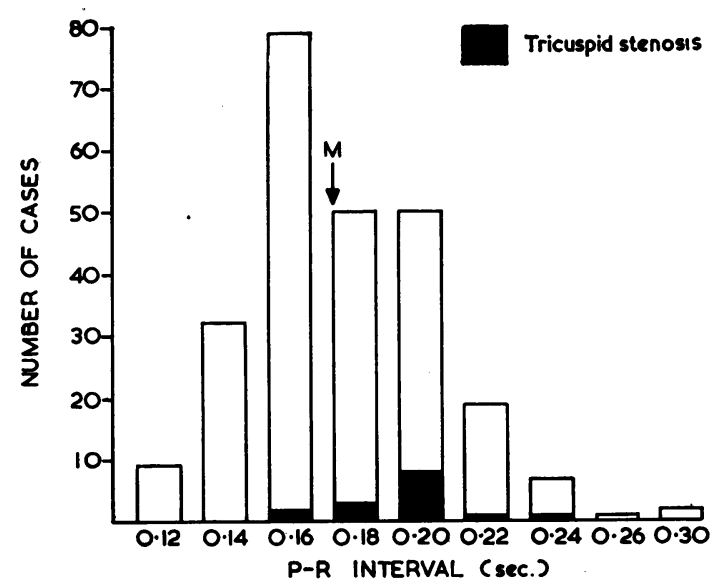

FIG. 6.-Distribution of $P-R$ interval in 250 cases of mitral stenosis without tricuspid disease and in 14 cases of mitral stenosis with organic tricuspid disease.

$$
\mathbf{M}=\text { mean }
$$

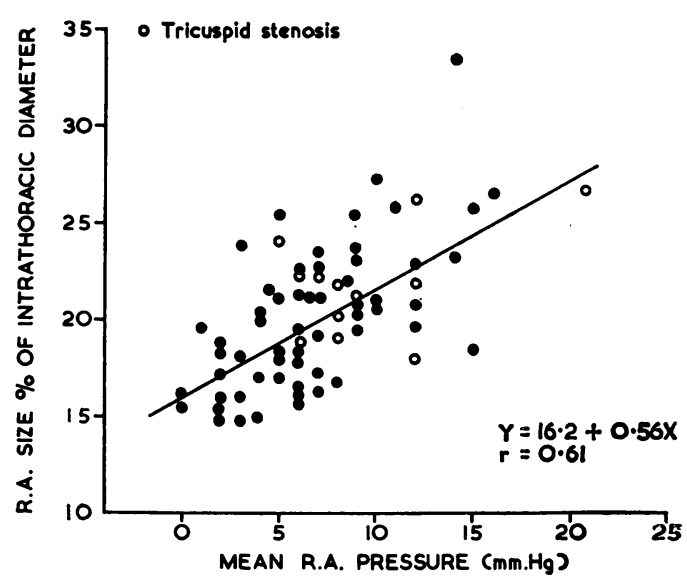

Fig. 8.-Correlation between mean right atrial pressure and radiographic enlargement of right atrium in 70 patients with mitral stenosis, including 12 with organic tricuspid disease.

right atrial enlargement but without the murmurs of organic tricuspid valve disease. Clearly enlargement of the right atrium is not by itself an indication of tricuspid stenosis.

Pulmonary Arterial and Venous Hypertension. In our series of patients with rheumatic heart disease radiographic enlargement of the pulmonary artery has been a good sign of pulmonary arterial hypertension and usually, but not always, of severe mitral stenosis. Occasionally severe pulmonary hypertension results from dominant mitral incompetence. Such hypertension, however, is mainly related to the pulmonary vascular resistance and in patients with the same degree of obstruction at the mitral valve there is a remarkable and unexplained variation in the response of the pulmonary arterioles. Theoretically, in tricuspid stenosis, the pulmonary artery is "protected" in the sense that a rise in pulmonary pressure is restricted by limited pulmonary blood flow consequent upon the tricuspid disease.

Pulmonary venous hypertension from obstruction at the mitral valve will be similarly limited, the lungs will appear relatively clear and without the characteristic transverse septal lines in the costophrenic angles. However, it is apparent from our data that enlargement of the pulmonary artery and septal lines may be present with severe tricuspid stenosis, and this has also been noted

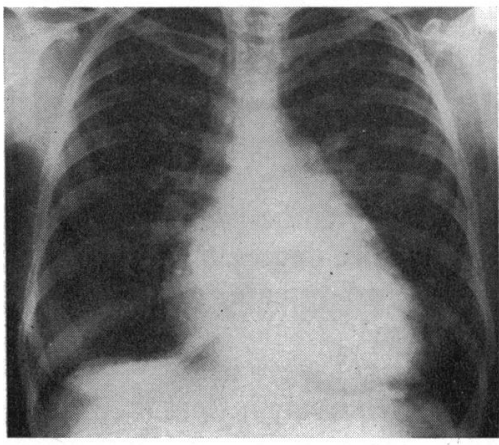

A

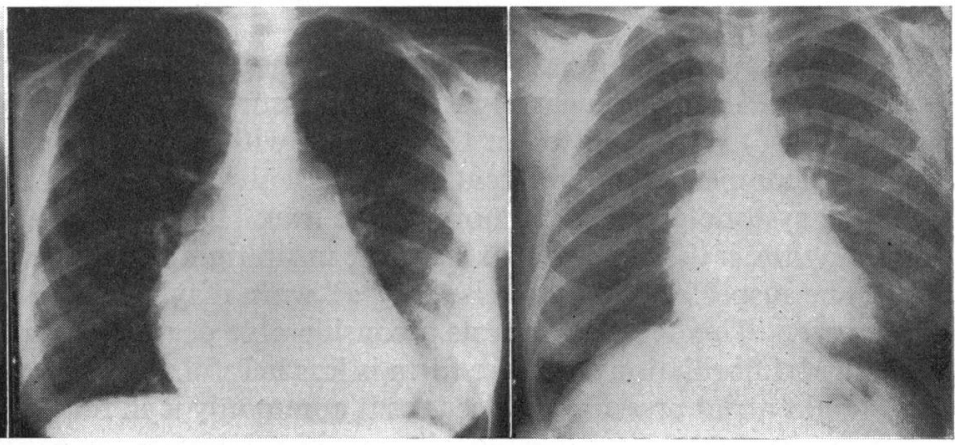

B
$\mathrm{C}$

FIG. 7.-(A) Chest radiograph in a patient with severe tricuspid and mitral stenosis; note right atrial enlargement, and clear lung fields. (B) and (C) Other patients with severe tricuspid stenosis showing pulmonary artery enlargement (B) and pulmonary venous congestion with septal lines (C). 
by Goodwin et al. (1957). Presumably the findings depend not only on the degree of obstruction at each valve but the order of development. The presence of septal lines indicates that the mitral valve offers a greater resistance to blood flow than the tricuspid, since the rate of flow through both valves is the same, and septal lines are evidence of a left atrial pressure exceeding $20 \mathrm{~mm}$. Hg (Rossall and Gunning, 1956). As discussed below, this does not imply that the blood flow is limited more by the mitral valve obstruction than by the tricuspid.

Intracardiac Pressures. A small diastolic pressure gradient across the tricuspid valve may be overlooked at cardiac catheterization. In addition unless records are made at a fast paper speed, a brief early diastolic dip in the right ventricular pressure or an artefact produced by an underdamped catheter-manometer system may be mistaken for the true right ventricular diastolic pressure, and a gradient suspected where none exists.

If a pressure gradient exists in diastole the tricuspid valve is abnormal. The pressure gradient may be due to pure stenosis at the valve, or to increased flow through a narrowed but predominantly incompetent valve. Yu et al. (1956) have also claimed that a small gradient may occur in functional regurgitation through a normal but stretched valve. The problem is to distinguish the gradient which is due to severe tricuspid stenosis.

The magnitude of the valve gradient itself bears no close relation to the degree of stenosis, as is clear from our data (Table I). Predominant tricuspid regurgitation may be associated with a large gradient (up to $11 \mathrm{~mm}$. in this series) due to increased flow with relatively little narrowing of the valve. According to Goodwin et al. (1957) a gradient exceeding $5 \mathrm{~mm}$. $\mathrm{Hg}$ is good evidence of severe stenosis but in three of the present patients such gradients were due to predominant incompetence, without operable stenosis. If the cardiac output is low and there is no reflux, severe stenosis may be present with only a small gradient. Flow through an orifice is related to the square root of the gradient; hence small variations in flow are associated with larger variations in pressure. Finally, cases in sinus rhythm have a smaller mean gradient for the same degree of stenosis than do those with atrial fibrillation (Fig. 2 and Table I).

Analysis of the right atrial wave form may be helpful. Functional tricuspid regurgitation can usually be distinguished from that due to organic disease (McCord and Blount, 1952; Messer et al., 1950; Müller and Shillingford, 1954). In functional regurgitation the $x$ descent following valve closure is reduced or abolished because the systolic wave in the right atrium begins relatively early. When the valve opens pressure falls rapidly and hence there is a steep $y$ descent. There is only a small gradient across the valve (Fig. 9A). In organic regurgitation, which is always associated with stenosis, the factor of obstruction to flow is added: the normal $x$ descent is retained, the systolic wave is late and less conspicuous, the $y$ descent is slow, and there is a diastolic pressure gradient across the valve (Fig. 9B). It is in this type of organic incompetence that the difficulty in assessing the degree of stenosis occurs, since a considerable diastolic gradient can occur in the presence of dominant incompetence.

In sinus rhythm analysis of the right atrial wave form in terms of the height of the " $a$ " and of the systolic waves and the mean right atrial pressure may be helpful. Fig. 10 shows the " $a$ " and the systolic ("s") waves plotted in the patients with tight stenosis and in the patients with dominant organic incompetence. Differentiation is not always good but in general if the " $a$ " wave exceeds the maximal systolic pressure by more than $5 \mathrm{~mm}$. $\mathrm{Hg}$ severe stenosis is likely to be present. Also, in sinus rhythm, if the " $\mathrm{s}$ " wave exceeds the mean right atrial pressure a severe degree of incompetence should be suspected. On exercise the "s" wave may increase to a relatively greater degree than the " $a$ " wave. This feature suggests a considerable degree of regurgitation.

In atrial fibrillation the wave form is less helpful. The most prominent wave is always systolic. 'If the right atrial pressure is raised, as it commonly is in fibrillation, a relatively insignificant regurgitant jet can produce a late systolic wave in the presence of tight stenosis. This has been noted before by Goodwin et al. (1957) and by Reale et al. (1956). Such a wave, therefore, does not preclude a dominant stenosis and the need for tricuspid valvotomy.

The change in the pressure gradient across the valve on exercise was studied in seven patients and 


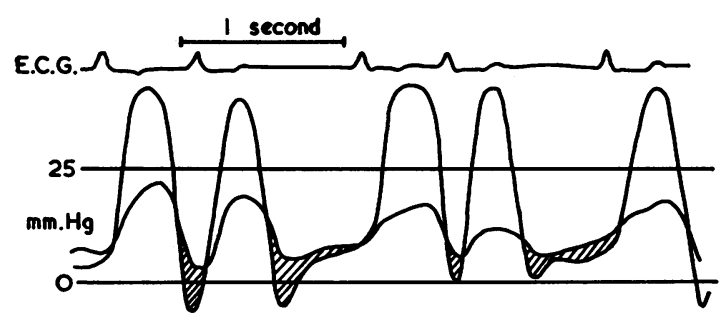

A
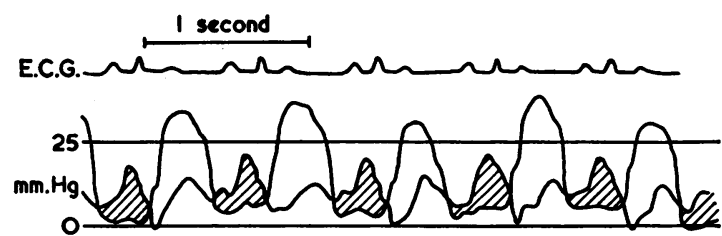

B

Fig. 9.-Superimposed right atrial ventricular pressure records to show differences between (A) functional tricuspid incompetence and (B) organic tricuspid incompetence.

found to be variable: little or no increase occurred in some cases in which, however, the increase in cardiac output was only slight; and only in the cases with arrhythmia were large rises in gradient (up to $10 \mathrm{~mm}$. $\mathrm{Hg}$ ) obtained. This did not prove to be a useful differentiating point between stenosis and incompetence. Good evidence of tight stenosis was the observation that during a long diastole in patients with fibrillation the diastolic pressure in the right ventricle rose only gradually to approach the right atrial level. Absence of transmission of the "a" wave through the tricuspid valve to affect the right ventricular pressure was noted in all cases with stenosis, but also in some with severe regurgitation.

Valve area calculations in patients with incompetence are of limited value and may be misleading, because they are based on measurements of pressure gradients and flow which cannot take account of regurgitation.

Analysis of the records shows that the most reliable evidence of tricuspid valve obstruction comes from the changes of pressure with respiration (Table IV). As discussed earlier, normally respiratory changes in intrathoracic pressure have little or no effect on the right atrial and right ventricular pressures, since, with the tricuspid valve open, these chambers are in free communication with the general venous system. However, in tricuspid obstruction the right ventricular pressures show abnormally large respiratory variations, while the right atrial pressures vary little (Fig. 11). In effect, the gradient across the valve in diastole varies with respiration. Fig. 12 shows the change in this gradient during normal respiration in the patients with tight tricuspid stenosis and in six other patients with a tricuspid valve gradient and dominant incompetence. This gives good differentiation. It corresponds to the auscultatory finding of the changing diastole murmur.

Valve Area Calculations. The area of the tricuspid valve calculated by the formula of Gorlin and Gorlin (1951) is shown for each case in Table IV. There is rather poor agreement with the size of the valve found at operation. The errors which are inherent in the estimate include those of the measurement of cardiac output by the Fick principle, of the diastolic filling time, and of the valve gradient. The gradient is more directly measured than in the case of the mitral valve but is usually smaller than in severe mitral stenosis and indeed unless especially looked for may escape notice at cardiac catheterization. The smaller the valve gradient the less accuracy can be expected from the valve area calculations.

The major source of inaccuracy is associated valve regurgitation which leads to an underestimate of the valve area (Table IVB). The reason for this is that blood flow

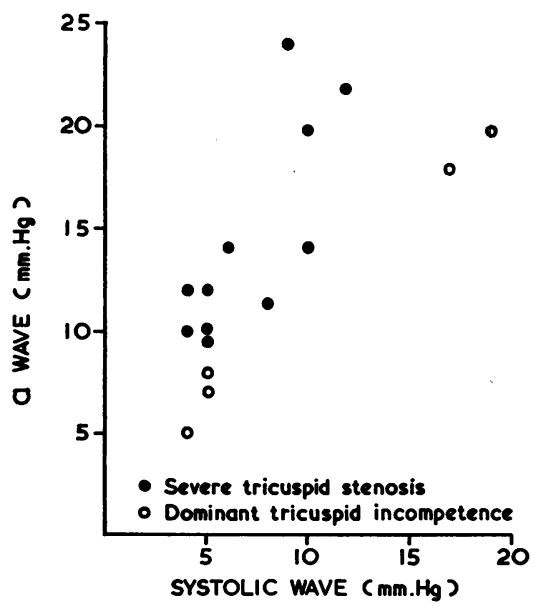

FIG. 10.-Height of "a" wave plotted against maximal right atrial systolic wave in patients with organic tricuspid disease. 


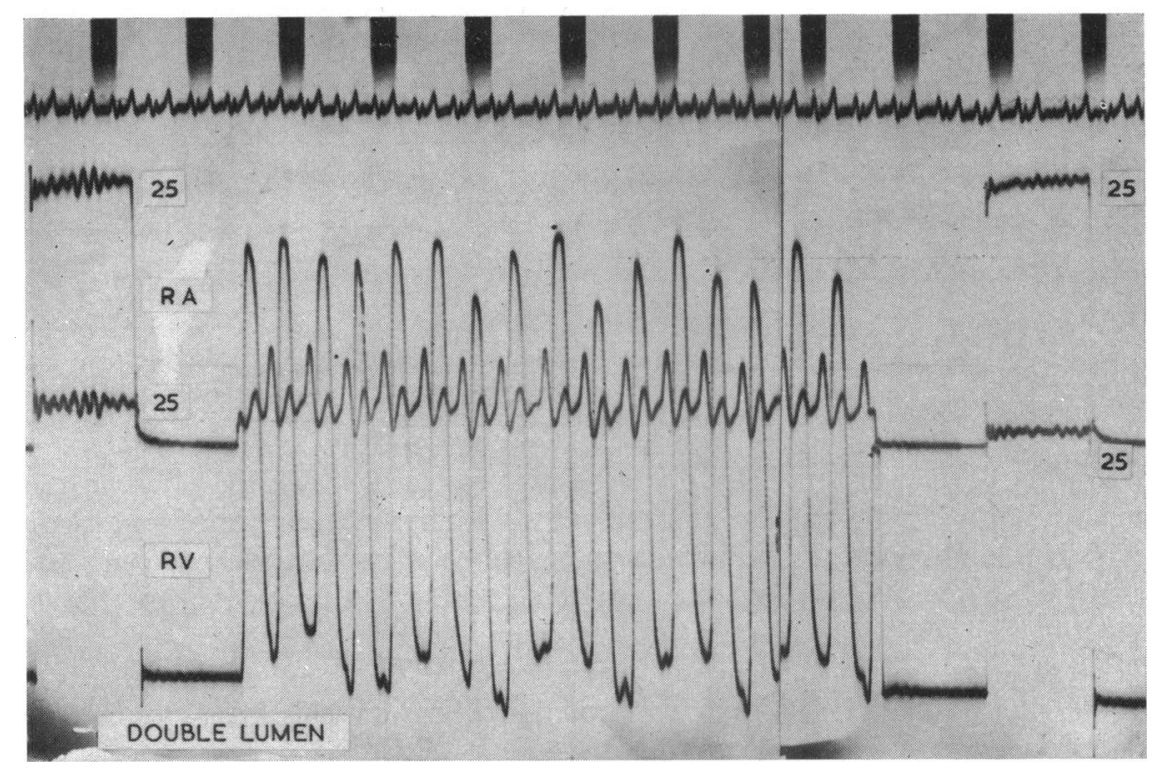

FIG. 11.-Tricuspid stenosis. Simultaneous right ventricular and right atrial pressures showing effect of respiration on ventricular diastolic pressure with no effect on right atrial pressure.

through the tricuspid valve in diastole cannot be measured but exceeds the cardiac output which is the figure that has to be used in the calculation.

It must of course also be appreciated that as in the case of the mitral valve the estimate of size made by the surgeon is only approximate. The shape of the stenosed valve may be very different from that of the exploratory finger and the force used in palpation may separate the cusps to a greater degree than the blood stream does.

The post-operative studies show that after adequate valvotomy tricuspid valve gradients, though considerably reduced, still persist: cardiac output remains low despite satisfactory

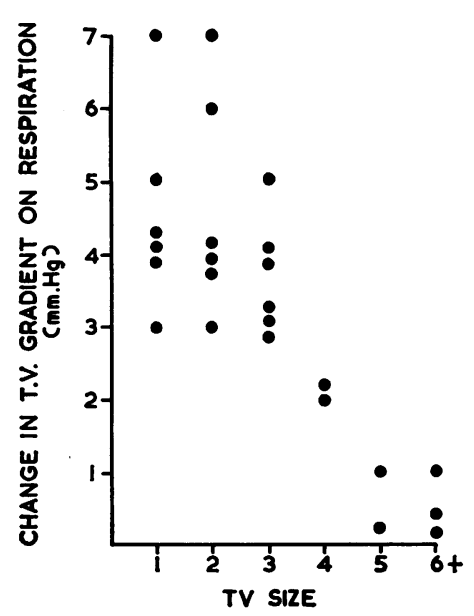

FIG. 12.-Change in transvalvular pressure gradient with normal respiration related to the degree of tricuspid valve narrowing. relief of symptoms. This finding may be compared with that of Donald et al. (1957) in relation to mitral valvotomy, when good symptomatic results were associated with relatively small hæmodynamic improvement. This serves to emphasize two points: first that the hæmodynamic result of valvotomy falls considerably short of what appears to the surgeon to be an excellent anatomical result, and secondly that the difference in orifice size between a stenosed valve causing severe symptoms and one causing no symptoms is a very small one, i.e. the size of the valve in relation to symptoms is highly critical.

Hamodynamic Effects of Tricuspid Stenosis. From the equation relating valve size, pressure gradient, and flow it can be seen that flow through a valve is a function of two factors, the size of the valve, and the square root of the pressure gradient across it,

$$
F=k \cdot r^{2} \sqrt{\Delta \mathrm{P}}
$$

where $F=$ flow, $k=$ constant, $r=$ radius of open valve, $\Delta \mathrm{P}=$ pressure gradient. 
TABLE IX

Mitral Stenosis: Comparison of Groups With aNd without Tricuspid Stenosis

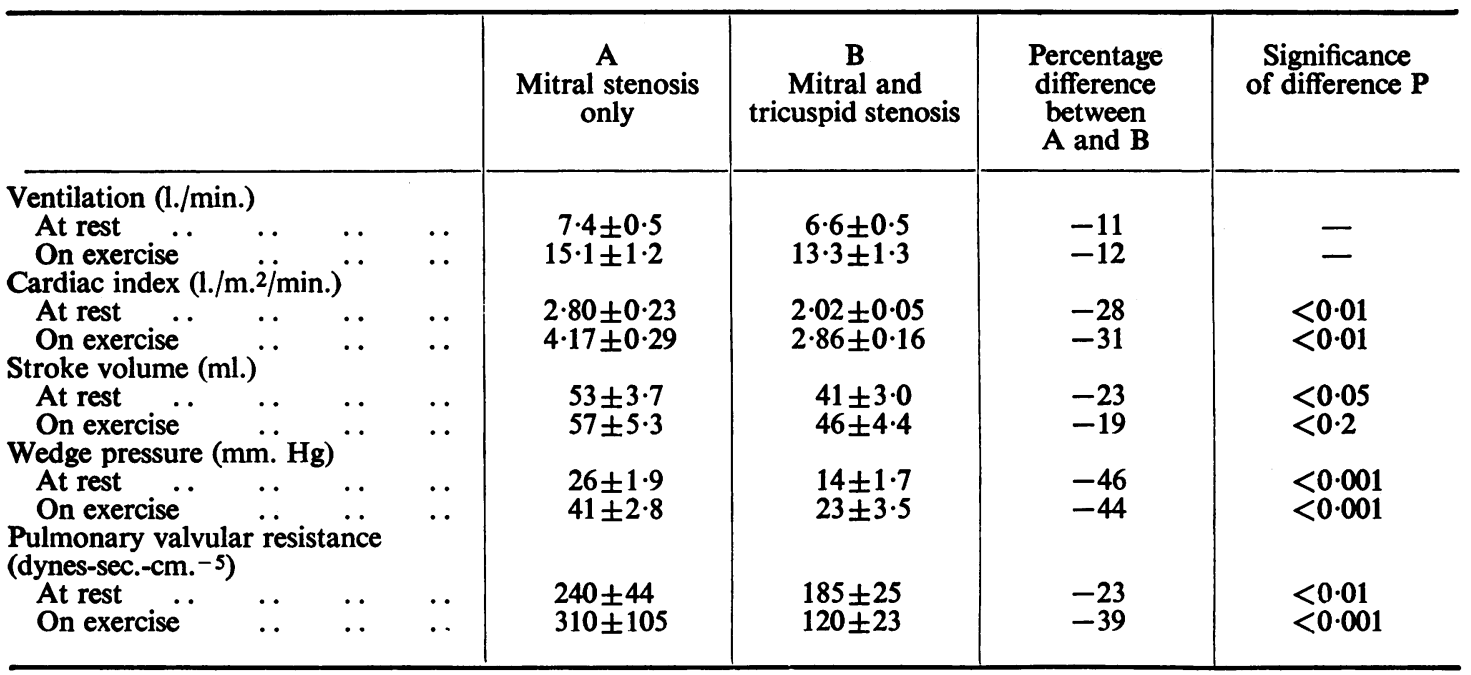

Assuming competence of the valves, flow through the mitral and the tricuspid is the same, and the valve with the higher gradient is the smaller in size. However in the case of the mitral valve $\Delta P$ can rise to a high level $(20-40 \mathrm{~mm}$. $\mathrm{Hg}$ ) because of the small volume and compliance of the pulmonary venous-left atrial system, and the fact that the right ventricle beats more forcibly, and may hypertrophy, when the pulmonary resistance is raised. In the case of the tricuspid valve, on the other hand, $\Delta \mathrm{P}$ has never in our experience exceeded $12 \mathrm{~mm} . \mathrm{Hg}$, and development of a higher pressure is unlikely because of the relatively large volume and high degree of compliance of the systemic venous -right atrial system. Because of this difference between the pressures which can be generated in the two atria, therefore, the limiting factor in the cardiac output may be the tricuspid valve rather than the mitral valve, and this may be the case even when the tricuspid is slightly the larger of the two. In terms of restriction of blood flow the critical valve size may be somewhat larger for the tricuspid than for the mitral valve.

When both valves are stenotic it may be possible to assess, hæmodynamically, which is the narrower. It is not possible, however, to assess the effect on the patient's over-all cardiac function of each valve defect. Consequently we have compared cardiac function in two groups of patients with mitral stenosis of equal severity, one group having in addition tricuspid stenosis (Table IX). In the group with stenosis of both valves the cardiac outputs were lower at rest and on exercise than those in the control group in which only mitral stenosis was present (Fig. 13). The difference suggests that flow obstruction at the tricuspid valve may be the limiting factor in cardiac output in many cases. In the tricuspid group mild exercise caused the oxygen saturation of the mixed venous blood to fall to levels of $30-40$ per cent.

Comparison of the pulmonary arterial wedge pressure in the two groups confirms that in most cases tricuspid stenosis is the limiting factor in blood flow. Despite severe mitral stenosis, only modest increases in wedge pressure occurred in most patients even on exercise. This indicates that the mitral stenosis, however severe anatomically, is not the limiting factor in restricting cardiac output. The difference between the cardiac outputs of the two groups on exercise was contributed to almost equally by stroke volume (smaller in the case of the tricuspid group) and by heart rate, which was slightly lower at rest in the tricuspid group (mean of 74 a minute against 80 a minute) and showed a much smaller increase on exercise (mean of 93 a minute against 110 a minute). The reason for the difference in heart rate is unknown. The other striking difference shown between the two 


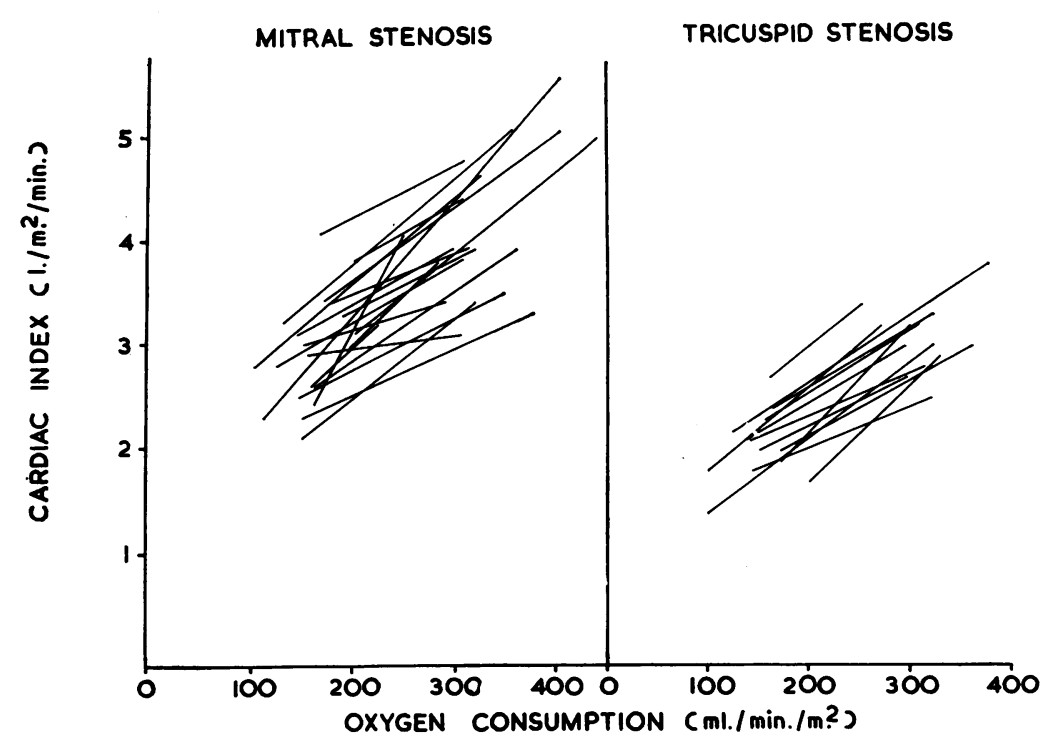

Fig. 13.-Cardiac index at rest and on exercise in 20 patients with mitral stenosis without tricuspid disease and in 13 with mitral stenosis with associated tricuspid stenosis.

groups is the pulmonary vascular resistance. In normal subjects it falls on exercise. In mitral stenosis the pulmonary vascular resistance was high and generally increased on exercise. The group of patients with tricuspid stenosis showed the normal response predominantly, though some patients with high wedge pressures showed the mitral type of response.

The importance of right atrial contraction as reflected in the " $a$ " wave in maintaining flow is shown by a comparison of the results in atrial fibrillation and flutter when, for a given degree of stenosis, much larger mean gradients across the valve were seen and were associated with higher mean pressures as reflected in the jugular veins (Fig. 2). This was also observed by Killip and Lukas (1957). It is clearly an advantage that the pressure gradient across a valve should be applied only at the time when it is hæmodynamically effective, i.e. when the valve opens in diastole. A brief pressure pulse is rapidly dissipated in the systemic venous system (see Fig. 4) and does not result in a sustained rise in mean venous pressure such as occurs in cardiac failure with tricuspid incompetence and the resultant deleterious effect on the viscera, particularly the liver and kidneys. With the onset of atrial fibrillation this hæmodynamic advantage is lost and high mean venous pressures occur. It is probably for this reason that cardiac cirrhosis of the liver is rare in patients who maintain sinus rhythm.

Reasons for Tricuspid Valvotomy. Tricuspid valvotomy was first reported by Brofman (1953). It has rarely been performed, partly from the difficulty of making the diagnosis of tight tricuspid stenosis, but also because of the widely-held opinion that the lesion is a benign one, or even beneficial in preventing secondary cardio-pulmonary effects of mitral stenosis. A contrary view, however, is supported by the following points. Patients may fail to improve after adequate mitral valvotomy because of unrelieved tricuspid stenosis. This was most convincingly demonstrated in a case reported by Hollman (1956). A woman of 24 with mitral and tricuspid stenosis was severely disabled by breathlessness and angina of effort. Mitral valvotomy improved the breathlessness slightly but made the angina worse; later partial relief of the tricuspid stenosis gave considerable symptomatic relief. Other similar cases have been reported by Chesterman and Whitaker (1954), O'Neill, Janton, and Glover (1954), Trace, Bailey, and Wendkos (1954), and Pantridge and Marshall (1957). 
Tricuspid stenosis can cause severe symptoms of effort dyspnœa and fatigue presumably due to a low cardiac output when the coexisting mitral stenosis, though severe anatomically, is relatively unimportant hæmodynamically. The symptoms of tricuspid stenosis are not distinguishable from those due to mitral stenosis. Since in many cases, however, pulmonary arterial wedge pressures are scarcely raised in exercise, the symptoms are not attributable to mitral stenosis itself. Breathlessness in heart disease is probably caused in various ways. In mitral stenosis decreased lung compliance due to pulmonary venous congestion is thought to contribute. In many other types of heart disease, however, this cannot be a factor and tricuspid stenosis falls into this category. The feature common to these diseases is a low cardiac output, inadequate to sustain a high rate of body metabolism without tissue anoxia.

The so-called protective role of tricuspid valvular disease in mitral stenosis, while relieving dyspnœa, operates by placing a restriction on the venous return to the ventricles and reducing the cardiac output. Relief from one form of disability is gained at the price of another. Where the disability is at least moderate and the diagnosis of severe tricuspid stenosis can be made with confidence, there is a clear case for surgical treatment.

\section{SUMMARY}

The diagnosis, circulatory effects, and surgical treatment of rheumatic tricuspid stenosis associated with mitral stenosis is discussed in relation to 17 patients subjected to combined valvotomy.

The diagnosis of tricuspid stenosis may be difficult and is frequently overlooked. Although a large flicking " $a$ " wave in the venous pulse, a tricuspid diastolic murmur, right atrial enlargement in the radiograph, right atrial hypertrophy in the electrocardiogram, and a pressure gradient across the tricuspid valve in diastole, offer presumptive evidence for tricuspid stenosis, each of these features may occur in other conditions. Large "a" waves occur in pulmonary stenosis, in pulmonary hypertension, including that of mitral stenosis, and in organic tricuspid incompetence. There is, however, a particular pattern of a "flicking" "a" wave unaccompanied by a systolic wave which is characteristic of severe tricuspid stenosis.

Tricuspid diastolic murmurs may occur in dominant tricuspid incompetence. They indicate organic tricuspid disease but are no guide to the severity of the stenosis.

Tall $\mathbf{P}$ waves in the electrocardiogram and right atrial enlargement in the radiograph though present in tricuspid stenosis are common findings in tricuspid incompetence and in right ventricular hypertrophy with a normal tricuspid valve. Enlargement of the pulmonary artery, congestion of the lung fields, and right ventricular hypertrophy do not exclude severe tricuspid stenosis. A pressure gradient in diastole across the tricuspid valve occurs both in dominant stenosis and in dominant organic incompetence and is unreliable as a guide to tricuspid stenosis of a severity requiring operation. Valve area calculations are similarly unreliable if incompetence is present.

Atrial fibrillation increases the difficulty of diagnosis. When tricuspid disease is present with fibrillation, a prominent systolic wave in the venous pulse may be associated with severe stenosis and only minor regurgitation.

The presence of any one of these features should raise the suspicion of severe tricuspid stenosis, and a combination is strongly suggestive. The most consistent confirmatory evidence of severe stenosis in the presence of a tricuspid pressure gradient proved to be the dissociation of right atrial and right ventricular diastolic pressures during respiration.

The relation of tricuspid murmurs to respiration is discussed, and it is pointed out that in severe tricuspid stenosis a systolic murmur from associated tricuspid incompetence tends to decrease on inspiration. The explanation for this is discussed in detail. Tricuspid stenosis causes a disability similar to that in mitral stenosis but which may be unrelieved by mitral valvotomy. The cardiac output is severely restricted both at rest and on exercise. When atrial fibrillation occurs the venous pressure remains permanently raised.

Symptoms were relieved in 12 patients after operation. Cardiac catheterization was repeated 
after operation in 5, and showed a reduction but not complete abolition of the valve gradient. Right atrial size did not decrease. Regression of the $\mathbf{P}$ pulmonale pattern in the electrocardiogram was usual but not always complete. Three patients died during the operation, but no death was considered to be due to the tricuspid valvotomy itself. Traumatic, i.e. operative valvular incompetence of significant degree, only resulted in one case. Two patients subsequently died, after one and two years respectively, and this was considered to be due to the over-all effects of severe rheumatic heart disease. Eleven of the 12 remaining survivors have remained well two to six years later: one had only a fair result.

\section{REFERENCES}

Aceves, S., and Carral, R. (1947). The diagnosis of tricuspid valve disease. Amer. Heart J., $34,114$.

Bailey, C. P. (1955). Surgery of the Heart. Lea and Febiger, Philadelphia.

- and Bolton, H. E. (1956). Criteria for and results of surgery for mitral stenosis. N. Y. St. J. Med., 56, 649, 825.

Brofman, B. L. (1953). Right auriculoventricular pressure gradients with special reference to tricuspid stenosis. J. Lab. clin. Med., 42, 789.

Cabot, R. C. (1926). Facts on the Heart, p. 159, 173. Saunders, Philadelphia.

Chesterman, J. T., and Whitaker, W. (1954). Mitral and tricuspid valvotomy for mitral and tricuspid stenosis. Amer. Heart J., 48, 631.

Cooke, W. T., and White, P. D. (1941). Tricuspid stenosis; with particular reference to diagnosis and prognosis. Brit. Heart J., 3, 147.

Coombs, C. F. (1924). Rheumatic Heart Disease. Wright, Bristol.

Davies, J. N. P., and Ball, J. D. (1955). The pathology of endomyocardial fibrosis in Uganda. Brit. Heart J., 17, 337.

Dennis, J. L., Hansen, A. E., and Corpening, T. N. (1953). Endocardial fibroelastosis. Pediatrics, $12,130$.

Donald, K. W., Bishop, J. M., Wade, O. L., and Wormald, P. N. (1957). Cardio-respiratory function two years after mitral valvotomy. Clin. Sci., 16, 325.

Ferrer, M. I., Harvey, R. M., Kuschner, M., Richards, D. W., and Cournand, A. (1953). Hemodynamic studies in tricuspid stenosis of rheumatic origin. Circulat. Res., 1, 49.

Fraser, H. R. L., and Turner, R. (1955). Electrocardiography in mitral valvular disease. Brit. Heart J., $17,459$.

Gibson, R., and Wood, P. (1955). The diagnosis of tricuspid stenosis. Brit. Heart J., 17, 552.

Goodwin, J. F., Rab, S. M., Sinha, A. K., and Zoob, M. (1957). Rheumatic tricuspid stenosis. Brit. med. J., 2, 1383.

Gorlin, R., and Gorlin, S. G. (1951). Hydraulic formula for calculation of the area of the stenotic mitral valve, other cardiac valves, and central circulatory shunts. Amer. Heart J., 41, 1.

Hollman, A. (1956). Tricuspid valvotomy. Lancet, 1, 535.

Killip, T., and Lukas, D. S. (1957). Tricuspid stenosis. Physiologic criteria for diagnosis and hemodynamic abnormalities. Circulation, 16, 3 .

Leatham, A. (1950). The chest lead electrocardiogram in health. Brit. Heart J., $12,213$.

Logan, A., and Turner, R. (1959). Surgical treatment of mitral stenosis, with particular reference to the transventricular approach with a mechanical dilator. Lancet, $2,874$.

Lyons, H. A., Kelly, J. J., Nusbaum, N., and Dennis, C. (1958). Right atrial myxoma. Amer. J. Med., $25,321$.

McCord, M. C., and Blount, S. G. (1952). The hemodynamic pattern in tricuspid valve disease. Amer. Heart J., 44,671 .

Messer, A. L., Hurst, J. W., Rappaport, M. B., and Sprague, H. B. (1950). A study of the venous pulse in tricuspid valve disease. Circulation, 1, 388.

Millman, S. (1943). Tricuspid stenosis and pulmonary stenosis complicating carcinoid of the intestine with metastasis to the liver. Amer. Heart J., 25, 391.

Müller, O., and Shillingford, J. (1954). Tricuspid incompetence. Brit. Heart J., 16, 195.

New York Heart Association (1953). Nomenclature and Criteria for Diagnosis of Diseases of the Heart and Blood Vessels, 5 th ed.

O’Neill, T. J. E., Janton, O. H., and Glover, R. P. (1954). Surgical treatment of tricuspid stenosis. Circulation, 9, 881 .

Pantridge, J. F., and Marshall, R. J. (1957). Tricuspid stenosis. Lancet, 1, 1319.

Paul, M. H., and Lev, M. (1960). Tricuspid stenosis with pulmonary atresia: a cineangiographic-pathologic correlation. Circulation, 22, 198.

Perloff, J. K., and Harvey, W. P. (1960). Clinical recognition of tricuspid stenosis. Circulation, 22, 346.

Ramsay, J. A. (1958). A bicycle dynamometer for exercise studies at cardiac catheterisation. J. Soc. Cardiol. Tech. Gt. Brit., 3, 184.

Reale, A., Goldberg, H., Likoff, W., and Denton, C. (1956). Rheumatic tricuspid stenosis. Amer. J. Med., $21,47$.

Rossall, R. E., and Gunning, A. J. (1956). Basal horizontal lines on chest radiographs; significance in heart-disease. Lancet, 1, 604.

Sepulveda, G., and Lukas, D. S. (1955). The diagnosis of tricuspid insufficiency. Clinical features in 60 cases with associated mitral valve disease. Circulation, 11, 552.

Simonson, E. (1961). Differentiation Between Normal and Abnormal in Electrocardiography. Mosby, St. Louis. 
Thayer, W. S. (1925). Notes on acute rheumatic disease of the heart. Bull. Johns Hopk. Hosp., 36, 99.

Thomas, P., and Dejong, D. (1954). The P wave in the electrocardiogram in the diagnosis of heart disease. Brit. Heart J., 16, 241.

Trace, H. D., Bailey, C. P., and Wendkos, M. H. (1954). Tricuspid valve commissurotomy with a one-year follow-up. Amer. Heart J., 47, 613.

Von Glahn, W. C. (1927). Rheumatic disease of the heart. Arch. Path. Lab. Med., 3, 355.

White, P. D. (1944). Heart Disease, 3rd ed., p. 629. Macmillan, New York.

Yu, P. N., Harken, D. E., Lovejoy, F. W., Nye, R. E., and Mahoney, E. B. (1956). Clinical and hemodynamic studies of tricuspid stenosis. Circulation, 13, 680. 